This item was submitted to Loughborough's Research Repository by the author.

Items in Figshare are protected by copyright, with all rights reserved, unless otherwise indicated.

\title{
Thriving, surviving and performing in late career: a mixed-method study of pathways to successful aging in organizations
}

\section{PLEASE CITE THE PUBLISHED VERSION}

https://doi.org/10.1093/workar/wax027

\section{PUBLISHER}

Oxford University Press (@ The Authors)

\section{VERSION}

AM (Accepted Manuscript)

\section{PUBLISHER STATEMENT}

This work is made available according to the conditions of the Creative Commons Attribution-NonCommercialNoDerivatives 4.0 International (CC BY-NC-ND 4.0) licence. Full details of this licence are available at: https://creativecommons.org/licenses/by-nc-nd/4.0/

\section{LICENCE}

CC BY-NC-ND 4.0

\section{REPOSITORY RECORD}

Taneva, Stanimira, and John Arnold. 2019. "Thriving, Surviving and Performing in Late Career: A Mixedmethod Study of Pathways to Successful Aging in Organizations". figshare. https://hdl.handle.net/2134/27299. 


\section{OXFORD}

\section{Work, Aging and Retirement}

\section{Thriving, Surviving and Performing in Late Career: A Mixed- Method Study of Pathways to Successful Aging in Organizations}

\begin{tabular}{|r|l|}
\hline Journal: & Work, Aging and Retirement \\
\hline Manuscript ID & WORKAR-2016-028.R4 \\
\hline Manuscript Type: & Empirical Article \\
\hline Keywords: & $\begin{array}{l}\text { Adaptation < Aging and Individual Differences, Selection, optimization, and } \\
\text { compensation theory < Aging and Individual Differences, Well-being < } \\
\text { Aging and Individual Differences, Job Performance < Work, Mid and late } \\
\text { career issues < Work, Strategic human resource management < Work }\end{array}$ \\
\hline
\end{tabular}

\section{SCHOLARONE}

Manuscripts 
Running head: PATHWAYS TO SUCCESSFUL AGING AT WORK

\begin{abstract}
We develop and test a model of successful aging at work in two studies. The first identifies key human resource (HR) practices that late-career workers find valuable, and explores workers' experiences of them. The second examines the role of those practices along with individual behavioral strategies in successful aging at work, as expressed by a sense of thriving and by three dimensions of job performance. We also introduce the new construct of surviving at work, contrasting with thriving. Study 1 reports qualitative data from interviews with 37 older workers (nearly all 55+) and 10 human resource managers in the United Kingdom (UK) and Bulgarian healthcare and information and communication technology sectors. Study 2 employs quantitative data from 853 UK older workers in the same two sectors. We find (Study 1) eight types of HR practices that seem particularly salient to older workers, and which they experience to varying extents. These practices cut across existing typologies, and we recommend them for future research. In Study 2 we find that selection, optimization and compensation strategies adopted by individuals are directly related to selfrated job performance, and mediate some of the effects of HR practices on job performance. In addition, optimization specifically affects performance via thriving, and to a lesser extent via surviving. The same is true for availability of HR practices. The results demonstrate the importance of both HR practices and individual strategies in fostering successful aging at work, and the important role of thriving in this process.
\end{abstract}

Key words: successful aging at work, thriving, surviving, mixed-method, performance, wellbeing, older workers, late career, lifespan 
Thriving, Surviving and Performing in Late Career: A Mixed-Method Study of Pathways to Successful Aging in Organizations

The purpose of this paper is to extend existing knowledge of the factors and processes underlying successful aging at work by exploring various pathways through which people in late career experience their workplace and perform their work. Integrating theoretical concepts from lifespan psychology, positive organizational behaviour and human resource (HR) management literatures, we examine the roles played by a range of personal, organizational, and contextual factors in shaping older workers' successful aging. In Study 1 we take a close look at the role of HR practices as potential contributors to thriving and surviving amongst older workers in ten organizations in the United Kingdom (UK) and Bulgaria. In Study 2 a model of successful aging at work is developed and tested using data from over 800 workers aged 55 years and over in four UK organizations in the health and ICT sectors.

Over the past two decades research, practitioner, and policy-making communities have acknowledged the aging of the world's population, and consequently the aging of the workforce, as a key societal challenge (e.g., Bohlinger \& van Loo, 2010). The need to sustain longer, but also healthy and productive working lives, across the developed countries and beyond (e.g., Eurofound, 2012) has prompted investigations into what might encourage and help older workers to extend their careers (e.g., Armstrong-Stassen, 2008a). Research has examined interactions between a variety of individual and contextual factors, such as person characteristics and self-regulation strategies (e.g., Warr, 1993; 2001; Abraham \& Hansson, 1995), job design (Truxillo, Cadiz, Rineer, Zaniboni, \& Fraccaroli, 2012), organizational climate and management strategies (Boehm, Kunze, \& Bruch, 2014), and wider environmental factors (Thrasher, Zabel, Wynne, \& Baltes, 2016). 
Recent studies have promoted the advantages of the lifespan perspective when studying aging in the workplace (Zacher, 2015a; Kooij, 2015a). In this context, the emerging concept of successful aging at work seems to offer a suitable framework for analyzing the drivers of and the processes underlying workers' longer and sustainable careers. Successful aging posits that an individual can enjoy good health over the lifespan through maintaining cognitive and physical abilities and fostering social engagement (e.g., Hansson, DeKoek, Neece, \& Patterson, 1997). Thus, the individual process of successful aging can be viewed as a person's on-going successful adaptation to age-related changes and environmental demands and opportunities. Criteria for successful aging should not only be maintenance of a level of functioning, but also growth (Zacher, 2015a,b).

Zacher $(2015 \mathrm{a}, \mathrm{b})$ suggests three types of intra-individual age-related trajectories of a work outcome (e.g., well-being or job performance) over time and across the working life cycle: usual aging at work (an intra-individual trajectory of a work outcome that matches the average age-related trajectory), unsuccessful aging at work (an intra-individual trajectory that demonstrates decline, i.e. deviates negatively from the average age-related trajectory of a work outcome), and successful aging at work (an intra-individual trajectory of a work outcome that deviates positively from the average age-related trajectory). Even an employee who has experienced a decline in a work outcome over time may be considered aging successfully at work if his/her trajectory is better than the average age-related trajectory (Zacher, 2015a,b). For Kooij (2015a,b), successful aging at work is understood as the sustainable maintenance of an individual's motivation, health, and workability across the working life cycle. Sustainability could be achieved through securing an on-going personenvironment fit, for example by employees actively shaping their environment by relocating and expanding resources (e.g., using selection, optimization and compensation strategies), 
crafting their jobs, and negotiating i-deals with their employers (e.g., Abraham \& Hansson, 1995; Kooij, Tims, \& Kanfer, 2016; Bal, 2015).

These conceptualizations of successful aging at work invoke the ideas of maintenance of functioning (especially Kooij) and also development/growth, which Zacher sees as a possibility in successful aging. Further, Kooij’s view of maintenance implies proactivity, learning and growth in order to adapt, so the two approaches are more similar than they might seem. Zacher stresses that the successful aging process can be documented only by analyzing the effects of age-related changes on work outcomes in the context of a variety of person and contextual factors. Further, he argues that as well as the importance of employee proactive behaviors (as suggested by Kooij), successful aging is a shared responsibility between employees and employers. Hence, "a comprehensive model should focus on person and contextual predictors (as well as their interactions) and outline potential age-differential effects of proactive behaviors on work outcomes" (Zacher, 2015b, p.330).

We take inspiration from these recent developments and pay a particular attention to the processes involved in successful aging at work. Similar to Zacher (2015a, b), we see growth as an indicator of successful aging at work. We wish to investigate growth processes and work effectiveness in late career in the context of both individual and organizational factors. In addition, we explore an alternative, less optimistic, pathway to aging in late career. We work with two criteria for successful aging at work (thriving at work and three indicators of job performance) and analyze the relationships between them. Ultimately, we aim to acquire new information about how both individuals and organizations can support successful aging in late career.

\section{Theoretical Foundations}

\section{Thriving and Surviving at Work}


Meaning of thriving at work. According to Franklin and Tate (2008), successful aging suggests individual's good health and vitality over the lifespan. Coming from a positive behavioral perspective, Spreitzer, Sutcliffe, Dutton, Sonenshein, and Grant (2005) define thriving at work as “...the joint sense of vitality and learning, which communicates a sense of progress or forward movement in one's self-development" (Spreitzer et al., 2005, p. 538). The two simultaneously occurring dimensions of thriving at work (vitality and learning) capture both the affective and cognitive aspects of psychological growth. Vitality reflects a person's energy and enthusiasm for work, while learning refers to building capacity by acquisition and application of knowledge. Thriving may serve as a gauge of a person's progress at work and, thus, help employees increase both their short-term functioning and longer-term development (Spreizer, Porath, \& Gibson, 2012).

Thriving at work is considered distinct from related constructs such as resilience, flourishing, subjective well-being, intrinsic motivation, and work engagement (Spreitzer et al., 2005; Carmeli \& Spreitzer, 2009; Spreitzer, Lam, \& Fritz, 2010). For instance, while subjective well-being captures mostly the hedonic perspective, thriving incorporates both hedonic and eudaimonic elements. In line with empirical evidence about age-related declines in social vitality and openness to experience (Roberts, Walton, \& Viechtebauer, 2006), it is expected that older workers would on average experience less vitality and learning than younger workers. However, in our recent published study we (Taneva, Arnold, \& Nicolson, 2016) showed that experiences of thriving are common among workers aged 55 years and over. Hence, it would be worth exploring this construct further specifically at the stage of late career.

Antecedents and outcomes of thriving at work. Organizational factors that may trigger experiences of thriving in the workplace include decision discretion (i.e. providing employees with opportunities for control and choices over their work), information sharing 
(i.e. transparency and good communication of key information across the organization), a climate of trust and respect, and access to performance feedback as well as general organizational knowledge (Spreitzer et al., 2010; 2012; Carmeli \& Spreitzer, 2009; Spreitzer \& Sutcliffe, 2007). In addition, Spreitzer and colleagues (2010) suggested that opportunities for innovation and meaningful work may contribute to workers' experiences of thriving. Findings from a diary study by Niessen, Sonnentag, and Sach (2012) supported this proposition.

Thriving at work has been found to be positively related to outcomes at individual level such as high job and career role performance, positive work-related behaviors (e.g., creative and innovative behaviors, organizational citizenship behaviors, learning from problems and obstacles, self-development), as well as work-related and overall well-being (Carmeli \& Spreitzer, 2009; Spreitzer et al., 2010; Porath et al., 2012). Overall, research demonstrates that thriving at work predicts high job performance above and beyond attitudinal variables such as job satisfaction and organizational commitment (Paterson, Luthans, \& Jeung, 2014). Further, thriving employees are reported to be more likely to contribute to their work beyond the specification of their role (i.e. extra-role performance) and to be more successful in developing supportive relationships with colleagues (Spreitzer et al., 2012; Porath et al., 2012). Thriving employees are likely to demonstrate proactive behaviors, which in turn provide them with more opportunities for learning and charge them with more energy (Fritz, Lam, \& Spreitzer, 2011; Spreitzer et.al., 2010; Paterson et al., 2014; Spreitzer \& Sutcliffe, 2007). The simultaneous experience of higher levels of both vitality and learning is crucially important for higher job performance (Spreitzer et al., 2012).

Conceptualizing surviving at work. Surviving at work is an emerging construct that closely relates to, and contrasts with, thriving at work. We conceptualize this as the individual's tendency to preserve their mental and physical resources by limiting their work 
activities and perspectives in order to cope with work conditions that are perceived as highly demanding (Taneva et al., 2016). In line with the socioemotional selectivity (SES) theory (Carstensen, 1992; Carstensen, Isaacowitz \& Charles, 1999) we suggest that surviving at work is driven by an orientation toward short-term goals, in contrast to thriving at work that is orientated toward growth (i.e. both short- and long-term goals) (see also Spreitzer et al., 2012). Further, we distinguish two dimensions of surviving at work: maintenance (meeting job demands) and preservation (of the status quo). Meeting job demands involves updating skills and using strategies to sustain an adequate performance, while preserving the status quo, is associated with a tendency to try to get by with existing skills and knowledge, as well as staying away from challenges such as workplace changes and (new) initiatives. To some extent this conceptualization resembles Ebner, Freund, and Baltes' (2006) distinction between maintenance and loss-prevention personal goals. Moreover, Ebner and colleagues found empirical evidence about different relations of maintenance and loss prevention orientations with older adults' well-being - somewhat positive for maintenance and slightly negative for loss-prevention. These two sub-dimensions of surviving at work are also perhaps conceptually close to the suggested by Zacher (2015a) constructs usual aging at work and unsuccessful aging at work. In this paper, we focus on surviving as preservation of the status quo because of its conceptual contrast with thriving at work, and as another potential route through which work performance might be affected. Thus, an employee who is concerned mostly with preserving his/her resources (status quo) would be likely to experience low levels of learning and perhaps relatively low levels of vitality.

\section{Self-regulation Strategies in Late Career}

Working is an integral part of most peoples' lifespan and, thus, a source of many opportunities for displaying the adaptive behaviors required for successful aging. In this paper, we focus specifically on the theory of selection, optimization and compensation (SOC) 
(Baltes \& Baltes, 1990), complemented by Carstensen's (1992) socioemotional selectivity (SES) theory.

Resource regulation through SOC behaviors. The SOC model proposes that successful lifespan development is a result of an individual's ability to allocate his/her resources in order to maximize age-related gains and minimize age-related losses (Baltes \& Baltes, 1990; Hansson et al., 1997; Rudolph, 2016). Three types of regulation processes (selection, optimization and compensation) frame the strategies employed by individuals in their attempts to adapt to both age-related changes and changes in their environment (in this case, workplace). Selection refers to the processes that restrict an individual's range of activities to a small number of important domains. Selection strategies are further divided into two subgroups: loss-based selection (focused on disengaging from unattainable goals due to a deficit of resources by e.g., selecting new goals) and elective selection (involves channeling resources by e.g., prioritizing goals). Optimization is demonstrated by activities aimed at increasing an individual's development resources and maximizing capabilities in order to attain goals (e.g., through training and development). Compensation occurs when unused resources have been activated or when lost resources have been replaced by new ones (e.g., using external hearing aids or asking for help). Thus, SOC strategies are aimed at three types of goals (regulation of loss, maintenance, and growth), toward which individuals could allocate their resources and adapt successfully. Moreover, the SOC strategies tend to operate together (Abraham \& Hansson, 1995; Freund \& Baltes, 2012).

Some empirical studies, starting with Abraham and Hansson's work in 1995, have shown the importance of using SOC strategies in the workplace, especially in late career. For instance, Bajor and Baltes (2003) reported that loss-based selection and compensation strategies lead to higher work performance of employees aged on average 43 years from the banking sector in the U.S. A recent systematic review and meta-analysis by Moghimi, 
Zacher, Shreible, and Van Yperen (2017) indicated that the use of each of the individual SOC strategies as well as the whole set of SOC strategies is positively related to age and overall job performance (with both self-reported job performance and non-self-reported job performance considered), job autonomy, satisfaction, and engagement. Since SOC strategies appear important for older workers, we would like to learn more about how the use of these strategies is associated with the concept of successful aging at work.

Focusing on short- and long-term opportunities. The SES model proposes a fundamental role for time perception in the selection and pursuit of social goals. When time is perceived as open-ended (e.g., at younger ages) individuals are likely to focus on long-term knowledge-related goals (e.g., learning). In contrast, when time is perceived as limited (e.g., at older ages), individuals may prioritize short-term emotional goals (e.g., focusing on meaningful activities and/or relationships). This shift toward emotional goals at older ages is facilitated by improved emotional regulation (Carstensen et al., 1999, 2011). Thus, older workers may be more likely to value positive social interactions (such as good relationships with colleagues and opportunities to transfer knowledge) than strive for (e.g.,) promotion (see Truxillo et al., 2012). In contrast to the SOC model, not many studies have explored empirically the applications of SES theory in the workplace so far. Among those which have, a meta-analysis by Kooij, De Lange, Jansen, Kanfer \& Dikkers (2011) showed a positive relationship between age and strength of social motives among certain subgroups of workers. In a study with 133 workers from a manufacturing company in Germany, Zacher and Frese (2011) found that job complexity and use of SOC strategies were positively related to focus on opportunities. A recent literature review by Rudolph (2016) emphasized that older workers alter their time horizons with respect to their occupational futures. We acknowledge the need for more evidence of the empirical applications of SES theory in the workplace. 


\section{Conceptualizing thriving and surviving at work from a lifespan developmental}

perspective. Although Spreitzer and colleagues do not conceptualize thriving at work in a lifespan framework, this construct seems relevant to both SES and SOC models. From a SES perspective, thriving at work implies an orientation toward both short- (such as focus on meaningful experiences) and long-term (such as learning) goals (see Spreitzer et al., 2012). Moreover, thriving has been associated with organizational antecedents such as opportunities for knowledge and information sharing, and access to meaningful work (see Spreitzer et al., 2007; 2009; 2010; 2012). From a SOC point of view, thriving is clearly described by a process of growth (see Spreitzer et al., 2005; 2010). In contrast, the protecting status quo aspect of surviving at work is viewed mostly as a passive coping strategy. Hence, surviving as protecting the status quo is expected to be negatively associated with work well-being and job performance.

\section{The Role of Human Resource Practices in Late Career}

Utilization of HR practices for older workers. The availability and/or uptake of human resource practices has been found to be positively related to a number of individual work outcomes, including job performance and intention to extend working lives (e.g., Armstrong-Stassen, 2008a,b). For instance, results from a Norwegian study by Kuvaas and Dysvik (2009) showed that perceived investment in employee development was related to different facets of work performance through intrinsic motivation. Some research in the last decade has focused on the HR policies and practices that may be particularly important for older workers and how the effects of HR practices vary with age (e.g., Armstrong-Stassen, 2008a,b; Kooij, Guest, Clinton, Knight, Jansen, \& Dikkers, 2013). Armstrong-Stassen and Templer (2005) observed that although employers in Canada were likely to provide access for older workers to training and retraining, less than 10 percent of the employers were highly engaged in doing this. In addition, organizations were not very committed to adapting 
training in order to accommodate older workers, or to providing age-awareness training for managers.

Some researchers have emphasized the importance of the context. For instance, Barnes, Smeaton, and Taylor (2009) noted that in the United Kingdom organizational size, extent of unionization, and proportion of female and professional employees were all positively correlated with the presence of formal pro-age policies. If any specific arrangements (e.g., flexible working options) were available, they were more often a result of informal practice or case by case solutions than a product of a formal strategy, and often were not confined to older workers. A U.S. study from the same year (Besen \& McNamara, 2009) found that $60 \%$ of the participating organizations had some initiatives in place to attract, engage and retain older workers. However, many of the managers and HR professionals did not have the necessary skills to provide career coaching for older workers. Older workers themselves were likely to be hesitant to raise issues or make requests. Tros (2010) found that in some countries (e.g., the Netherlands and Denmark) companies supported longer working lives to a greater extent than in others (e.g., Germany and Belgium).

Differential effects of HR practices in late career. Recently, there has been a shift from advocating the provision of HR practices that would mostly help workers to cope with reduced capacities to practices which can also develop older workers' capacity. For instance, coming from a lifespan developmental perspective, in a mixed-method study in the Netherlands, Kooij and colleagues (2014) conceptualized and operationalized four bundles of HR practices for aging workers: accommodative, utilization, maintenance, and development. Accommodative HR practices are associated with reducing job demands (e.g., additional leave and demotion). Utilization practices refer to supporting older workers by replacing unachievable job demands with more achievable tasks to utilize existing but perhaps underused resources. Maintenance HR practices (e.g., job security and flexible work 
schedules) are meant to help workers to maintain their current level of functioning, especially in the presence of new challenges or loss. Development HR practices (e.g., training and internal promotion) were those aimed at encouraging workers to achieve higher levels of functioning (i.e. growth).

Research findings on the effects of different HR practices on older employees' work outcomes so far have been mixed. In a study among over 4000 organizations in the Netherlands, Bal and Dorenbosch (2014) found that those with high proportions of older workers benefited (in terms of their performance) from work schedule practices, while organizations with high numbers of younger workers were more likely to benefit from development practices. Veth and colleagues (2011) discovered that maintenance HR practices and, more specifically, those related to reducing employees' job demands, were implemented far more frequently than development HR practices by organizations in the health sector. However, the development practices were more highly associated with job enrichment and self-efficacy (compared with maintenance practices). Kooij and colleagues (2013) reported that the association between development HR practices and well-being weakened with age, whilst the opposite was true for maintenance HR practices. In contrast, the development HR practices (more specifically, job enrichment practices) were associated with higher job performance among older (compared with younger) workers. It seems that as workers age, maintenance HR practices may help them to feel better, but development HR practices help them work better.

\section{The Two Studies Reported in this Paper}

A notable omission from studies of the effects of HR practices is a close analysis of which practices older workers (or any other workers) consider potentially valuable, why, and in what ways. An understanding of this, and of how such practices are perceived to work in practice, is important in identifying their actual and potential roles in successful aging. In 
Study 1 , which is qualitative, we seek to make a significant contribution to this endeavor. The results contribute to Study 2, where we respond to calls for analyses of successful aging that take into account both personal and organizational variables. We use quantitative data to test a proposed model where HR practices and SOC strategies affect thriving and surviving in the workplace, which in turn affect three facets of work performance.

\section{Study 1: Older Workers' Experiences of HR Practices in Late Career}

In Study 1 we aim to learn more about the actual and potential significance of HR practices in facilitating successful aging at work. We do this by interviewing late career employees and their HR managers. We are particularly interested in late career employees' evaluations of what available practices work (or could work) best for them, and what approaches are not preferred even if literature and organizational practice suggest otherwise.

\section{Method}

\section{Research Strategy}

We use the same research strategy and sample as in our previous paper (Taneva et al., 2016), which explored the conceptualizations of 37 older workers of aging in the workplace and, thus, can be used for further reference regarding the research method's details. However, this time we work with data that have not been used before and include an additional group of participants (10 HR managers). We adopt a contextual constructionist perspective (Madill, Jordan, \& Shirley, 2000) and a phenomenological psychological approach (Denscombe, 2007). This means that we seek to discover how our interviewees experience their organization's use of HR practices, and we assume that how these experiences are interpreted is influenced by the context (e.g., the nature of the work carried out by the organization) and constructed at least in part through social interactions at work. As recommended for this type of study by King (2004a), we used a non-probability sampling strategy to identify older workers (aged 55 years and over) for qualitative semi-structured interviews. 
We were concerned to ensure that we could capture a wide range of perceptions and experiences, and avoid our findings being context-specific. To this end, we focused on two European countries - Bulgaria and the UK - and worked in two languages (Bulgarian and English). These two countries differ in their national economies, cultures, policies, levels of awareness, and experiences regarding the organizational management of the aging workforce (EEO Review, 2012). For example, the UK is $10^{\text {th }}$ and Bulgaria $49^{\text {th }}$ on the Global AgeWatch index (HelpAge, 2015). Further, we worked in two industrial sectors - healthcare and information and communication technologies (ICT). We chose these sectors because of their economic significance, large numbers of employees, and on-going skill development. Also, we were attracted by the underlying contrasts between these two sectors in terms of workforce demographics, skill preferences, and age-sensitivity (Schwartz-Woelzl \& Healey, 2007, HOSPEEM, 2013). Informed by the example of Whitley (2016), we looked for patterns of themes across groups of participants (i.e. HR managers and older workers), sectors and countries.

\section{Organizational and Individual Participants}

Between September 2013 and January 2014, we recruited 10 employing organizations five in Bulgaria and five in the UK, six in healthcare and four in ICT. All the ICT organizations were large multinational companies (with over 1000 employees in their local offices), while all the healthcare organizations were public and, except one, large (with between 1000 and 3000 employees). All the large healthcare organizations but none of the ICT organizations were unionized. Also, the healthcare organizations had larger proportions of older workers $(55+)$ ranging from $20 \%$ to over $50 \%$. Contrastingly, the proportions of older workers in the ICT organizations varied between $1 \%$ and $12 \%$. In addition, healthcare organizations had large numbers of female workers (over 60\%), whilst the ICT organizations reported predominantly male staff (between $50 \%$ and $80 \%$ across organizations). All 
organizations, except for the Bulgarian health organizations, had formal equality and diversity policies in place. The range of HR services varied significantly across organizations from overall well-developed multi-service HR departments in the UK to a very limited (mostly payroll) HR function in some of the Bulgarian health organizations.

We interviewed a total of $10 \mathrm{HR}$ managers (one per organization) and 37 older workers (3-5 people per organization; 20 from healthcare and 17 from ICT; 20 from Bulgaria and 17 from the UK). Twenty-eight of the participating older workers were aged between 55 and 65 years, 5 were aged between 52 and 54 years, and 4 were aged 66 years and over. The mean age of the whole sample was 59 , with 60.7 for the healthcare sub-sample and 57.5 for the ICT sub-sample. Over $60 \%$ of interviewed employees were female. Most interviewed older workers were in management roles (about 50\% for healthcare organizations and about $75 \%$ for ICT organizations). Most workers (60-70\%) had been with their organizations longer than 10 years and many for over 20 years.

\section{Data Collection and Analysis}

We developed two semi-structured interview guides (one for older employees and one for HR managers) in two languages (Bulgarian and English). The two guides were very similar as most of the questions in them covered the same ground. They included general organization and participant background sections, and a set of broad open questions about the respondent's perceptions and experiences of organizational HR practices under the general headings of recruitment, flexible working options, job design, training and development, performance evaluation, compensation, recognition and respect, and retirement. The interview guides were piloted with older employees and HR managers from the two countries.

We approached the HR managers directly, while older workers were recruited through announcements on their organizations' intranet and, where possible, targeted emails. 
Volunteers to participate contacted us directly. All interviews took place between November 2013 and April 2014, were individual, and 86\% of them were conducted face-to-face on the premises of participants' organizations (vs. $14 \%$ over the phone). Interview duration was between 30 and 80 minutes. All interviews were preceded by documented informed consent of participants. Most interviews were voice-recorded except for five which were documented by notes at the time of the interviews. The voice recordings were transcribed and the interviewees were anonymized by codes. The transcripts of the interviews in Bulgarian language were translated into English. All transcripts were analyzed using an inductive thematic analysis procedure (King, 2004b; Braun \& Clarke, 2006). This technique is highly flexible and particularly suitable for qualitative research samples with over 30 cases (King, 2004a). Thus, it is very appropriate for our study, which focuses more on the clusters of meanings across the whole data set than on the within-individual patterns.

We developed a coding system by following the template analysis guidelines proposed by King (2004) and Braun \& Clarke (2006). Themes identified could appear anywhere in the transcript, and often occurred in more than one part of it. Then, we applied a validation technique as suggested by Campbell and colleagues (2013). This approach was particularly suitable for our study for two main reasons: i) it focuses on in-depth structured interviews and ii) it is useful where coding of the transcripts is applied by a single researcher. The initial version of the coding system included 8 primary codes corresponding to the main areas covered by the interview guides. This version was tested on a sample of interview transcripts using qualitative data software (NVivo 10), and was consequently revised and enriched by emerging codes. The second version included 8 main and 19 sub-categories, with the main categories identified based on their frequency of occurrence and apparent significance in the working lives of our respondents. They were somewhat different from the primary codes. Each category was operationalized by a definition and examples. At this point the coding 
system was communicated with the second author and tested for its validity as described by Campbell (2013). Based on this, the first author coded the remaining interview transcripts and finalized main and sub-themes within the entire data set.

\section{Results}

The eight key themes identified in this study were carried forward into the consecutive Study 2 as our measure of available HR practices. They are: (i) training to update current job skills; (ii) training to learn new skills; (iii) challenging and meaningful tasks or assignments; (iv) recognition of the significant role mature employees can play; (v) useful feedback from supervisor/manager; (vi) financial incentives to remain in the workforce instead of retiring; (vii) unpaid (additional) leave; and (viii) opportunities to work past retirement.

Table 1 shows the eight themes with exemplar quotes. We include some quotes that indicate a lack of a desired HR practice as well as those which indicate satisfaction with what was available where this reflects what was said to us, and what seemed to be significant to the respondent. Below we provide a brief summary of our findings regarding what was being said about HR practices and their importance. This uses, and also combines, the themes we identified.

\section{INSERT TABLE 1 ABOUT HERE}

\section{Training to Update Old Skills and Learn New Ones}

No HR manager in our study could provide or recall precise information about the participation rates of older workers in organizational training and development initiatives. Some organizations (mostly ICT) were more proactive than others in encouraging employees to participate in non-mandatory training activities. No organization in this study reported availability of training particularly designed for older workers, apart from the retirement- 
related courses offered in the UK organizations from both sectors. However, as Table 1 shows, some HR managers were concerned to ensure that refresher training was available to those who worked beyond retirement (see Armstrong-Stassen, 2008a).

The majority of older workers in our study expressed willingness for continuous learning and development (both formal and informal) and reported recent involvement in some forms and types of training (e.g., upgrading skills and developing new skills). Training was seen partly as a "maintenance" (Kooij et al., 2014) activity to preserve job competence, but also partly in developmental terms as increasing current and future competence, and not just in the current role (see Table 1). While general training opportunities were available to all, access to qualification options (subsidized by the employer) was thought to be available mainly to the younger and outstanding employees. Moreover, equal access to training and development in organizations was not necessarily perceived as meaning equal opportunities (Barnes et al., 2009). Many older workers across sectors and countries thought that the learning opportunities they had been offered were more suitable for people with less experience and in early career. This suggests that the low participation of older workers in training that is sometimes observed may be as much to do with older workers not seeing it as useful to them, as with any reluctance to learn new things (Armstrong-Stassen \& Templer, 2005). In the UK organizations, age-awareness training for managers was a small part of general diversity training. The Bulgarian health organizations did not have such practices at all.

\section{Challenging Tasks, Recognition and Feedback}

Some interviewees noted that the seniority and accumulated knowledge and skills of older workers gave them scope to make their jobs as challenging (or not) as they wished (see Table 1). Having interesting work which utilized their experience was seen as important by many respondents. This was connected with being recognized in the organization for their 
contribution and expertise, particularly being given autonomy and trusted to do the job without close supervision. This is consistent with Truxillo et al.'s (2012) proposition that autonomy is likely to be a key element in motivational jobs for older workers, and with the Kooij et al (2011) meta-analysis which found an age-related increase in autonomy motives. Those who wanted an easier time in the run-up to retirement generally mentioned reducing hours rather than having less demanding tasks. The possibility of additional leave was the most common manifestation of this, and is one of the themes shown in Table 1. This finding is in line with some of the effects of age-related changes on work motivation in the context of work-family conflict as explained by Thrasher and colleagues (2016). Most importantly, it supports the idea that lifespan theory applications in the workplace hold across national cultures. While reports about formalized job redesign practices were rare, many interviewees had positive experiences of informal practices, especially in the ICT sector. This corresponds to empirical findings from the leader-member exchange school about the benefits of managing workers through informal work arrangements (see Bal, 2015; Kooij et al., 2016; Martin, Guillaume, Thomas, Lee, \& Epitropaki, 2016). It seems likely that use of SOC strategies would enable the older workers to take advantage of opportunities to craft their job, not least because, as many have pointed out, SOC strategies can help to realize potential agerelated gains as well as to minimize potential losses (e.g., Zacher \& Frese, 2011; Kooij et al., 2016).

Several respondents referred to prizes available in their organizations for particularly good contributions such as a specific project or an idea that is adopted more widely. However, the kind of recognition most respondents seemed to value was more to do with being heard by their managers, being given the opportunity to move to roles where their expertise could be used, and sharing their accumulated knowledge with younger colleagues (see Table 1). Again, such perceptions perhaps reflect the idea of the increased value of 
emotional goals later in life, implied by the SES theory (see Carstensen, 1999; 2001; Kooij et al., 2011). For some respondents, the desire to be heard by managers extended to a wish for open communication and honest feedback, though not everyone thought this happened, and some noted that managers who were considerably younger than they were could be reluctant to be critical. Recognition and feedback were usually talked about in the context of day to day work and relationships, and rarely in the context of formal performance assessment and development processes. Once again, the importance of informal work arrangements in late career was emphasized (see Bal, 2015).

Despite the interest in developing new skills noted above in the comments on training, respondents generally construed challenge and recognition with reference to their existing knowledge, skills and accomplishments, not their potential to develop into new areas. This is consistent with Kooij et al.'s (2011) findings of (albeit weak) trends toward greater wish for use of skills and less wish for development with age, and with Carstensen's (1992) SES theory which posits that with increasing age there tends to be a shorter time perspective. Even so, Kooij et al. also found an age-related decrease in importance of recognition. This is not necessarily inconsistent with our findings, but recognition was certainly still important to these older workers.

\section{Extending Working Lives}

Respondents did not report availability of benefits tailored specifically for older workers. This reflects a more general caution on the part of HR managers about doing anything that might fall foul of equal opportunities legislation by favoring older workers at the expense of younger ones (see Barnes et al., 2009). However, some older workers felt that this apparent neutrality meant a lack of positive messages, where the only indicator of organizational appreciation was the absence of negative outcomes such as sanction or encouragement (by the organization) to retire. On the other hand, some benefits available to 
everyone were seen as attractive by older workers. They appeared to act as "to work" motivators (Kanfer, Beier, \& Ackerman, 2013) and acted as what Boehm and colleagues (2014) call age-inclusive HR where practices are available to all employees equally, whatever their age. The most obvious is the accumulation of a greater pension with increasing length of service, but others included vouchers, discounts, and subsidized healthcare. In the context of longer lives and (especially in the UK) threats to the viability of previously apparently "safe" pension schemes, financial incentives were salient to many respondents, despite the fact that most had passed the most financially pressing stage of their life, with children to care for and large loans to pay back for their home.

Few of the older workers talked specifically about working after retirement (most were not close enough to retirement to be considering this in detail), but the HR managers did. They reported being open to making arrangements for people who had retired to continue working in various flexible ways if they had valuable skills and/or experience. This can be considered career bridge employment (Wang, Zhan, Liu \& Schultz, 2008). As can be seen in the quotes in Table 1, it appears that this was a fairly frequent occurrence, which is why we have included it as a theme.

\section{Study 2: Testing a Model of Successful Aging at Work}

The aim of Study 2 is to introduce and test a new conceptual model of successful aging at work. Theoretically, this model builds upon the recent developments in the successful aging at work arena (e.g., Zacher, 2015a,b; Kooij, 2015a,b) and is an intersection between the lifespan developmental approach (e.g., SOC framework) and conceptualizations from the positive psychology and human resource management literatures (e.g., Spreitzer et. al., 2010; Kooij et al., 2013; 2014). Working with the eight HR practices identified as particularly salient for older workers in Study 1 (see Table 1), we explore the effects of the perceived availability of specific practices in combination with the individuals' use of proactive 
behaviors (selection, optimization and compensation) on three dimensions of job performance (task proactivity, in-role and extra-role performance). Most importantly, in this model we emphasize the role of workers' psychological experiences of thriving and surviving as mediators of the relationships of organizational and individual strategies with work outcomes.

\section{Research Hypotheses}

Associations between Organizational Practices, Personal Strategies, Thriving and Surviving at Work

As discussed earlier in this paper, strategic HR management is an important tool for organizations and their leaders to demonstrate consideration and support for employees (e.g., Armstrong-Stassen, 2008a,b; Kuvaas \& Dysvik, 2009; Kooij et al., 2013, 2014). One way to support workers is allowing opportunities for utilizing SOC behaviors (e.g., Müller, Weigl, Van der Heijden, Glaser \& Angerer, 2012; Rudolph, 2016). Although research to date has presented strong evidence of the role of various work-related antecedents of SOC strategies, only a few studies have addressed the relationships between organizational HR practices and SOC strategies (see Moghimi et al., 2017). For instance, in a sample of 1058 employees in a healthcare organization in the Netherlands, Bal and colleagues (2013) found that selection and compensation (but not optimization) strategies moderated the relationship between accommodative HRM and work engagement. In that study SOC strategies are seen mostly as compensators for developmental losses. However, in our recent research we found that, overall, older workers: i) conceptualize the process of aging at work in rather positive (e.g., development) than negative (e.g., decline) terms, and ii) attribute the use of SOC strategies more to their personal growth (e.g., increased experience and learning) than to experienced loss (e.g., declining energy and cognitive abilities) (Taneva et al., 2016). In addition, in Study 1 of this paper we found that older workers were likely to value HR practices that promote 
growth along with some practices that offer accommodation. Based on this, we assume that both developmental and accommodative HR practices could be antecedents of SOC behaviors in late career. For instance, the availability of opportunities to learn new skills through organizational training or access to challenging and meaningful tasks may increase the use of optimization strategies by older workers. Constructive feedback from line managers may encourage older employees to consider better their priorities (i.e. select), capitalize on their strengths (compensate) and/or enhance their potential (optimize). Based on the above, we hypothesize that:

H1: Availability of HR practices is positively related to use of SOC strategies at work.

It has been suggested that organizational leadership is a key driver for thriving at work (Spreitzer et al., 2010). Also, some HR practices have been shown to be antecedents of a number of positive individual work outcomes (e.g., well-being, performance, and intention to remain in the organization/workforce) (Armstrong-Stassen, 2008a,b; Veth et al., 2011; Kooij et al., 2013; Bal \& Dorenbosch, 2014), some of which have been considered positive outcomes of thriving at work too (Spreitzer et al., 2010; Porath et al., 2012; Paterson et al., 2014). Therefore, it is important to examine the role of HR management in relation to thriving at work. We anticipate positive associations between HR practices and thriving at work in late career (Taneva et al., 2016). For instance, HR practices that encourage employees' training and development as well as the update of current skills would be expected to have positive effects on thriving at work, mostly because of its learning dimension and its implicit orientation toward longer-term goals). HR practices that provide workers with access to meaningful, interesting and challenging jobs as well as approaches that demonstrate recognition and respect are expected to have positive relationships with older workers' experiences of thriving, because they will foster both high energy levels and learning. 
In addition, HR practices that encourage individuals' growth may contribute to increasing employees' resources (e.g., in terms of vitality, resilience, and development) and, therefore, help to reduce defensive survival strategies. For example, HR practices that facilitate the development of new skills or the update of current skills (especially in knowledge intensive sectors like the ones in our study) will be likely to boost employees' confidence and work capacity, and thus, extend opportunities for both personal and professional growth. In addition, incentivizing employees to extend their working lives may change their perceptions of limited remaining time (Zacher \& Frese, 2011; Rudolph, 2016) in the workplace and, thus, encourage a more proactive approach toward shaping one's late career. Hence, we predict that:

H2: Availability of HR practices is positively related to thriving at work.

H3: Availability of HR practices is negatively related to surviving at work.

Furthermore, to our knowledge no study on the relationships between SOC strategies and thriving at work has been published so far. This is a significant gap, because (as described in the previous section) SOC strategies have been shown to play an important role regarding workers' well-being and performance, especially in late career (e.g., Abraham \& Hansson, 1995; Moghimi et al., 2017). Also, it has been demonstrated that proactive individual approaches encourage workers' experiences of thriving (Fritz et al., 2011; Spreitzer et.al, 2010; Paterson et al., 2014). Therefore, SOC strategies may be an important antecedent of thriving at work. Since SOC strategies ensure the proactive self-regulation of individual resources, their successful use may contribute to preserving (and even increasing) workers' energy levels and maintaining (or improving) learning. This contrasts with the common view that SOC strategies compensate for developmental losses (e.g., Bal et al., 2013) and, thus, are more useful for maintaining than developing a person's capability in the workplace. Again, it is in line with our previous findings (Taneva et al., 2016) that many 
older workers viewed SOC strategies more in terms of a refined work approach (due to accumulated knowledge, experience, and confidence) than an attempt to make up for developmental losses.

Since the use of SOC strategies may help to add and/or reorganize resources (Abraham \& Hansson, 1995; Bajor \& Baltes, 2003), the employment of these strategies may contribute to increasing a person's work capacity (e.g., energy levels) and thus, reduce defensive surviving (protecting the status quo) experiences. In contrast, it could be argued that some SOC strategies (such as loss-based selection and compensation) are a consequence of loss of resources and therefore might be positively associated with a surviving orientation to work. However, generally, the individual's pro-active orientation is a core argument in the SOC model (see Rudolph, 2016). We therefore think it is more plausible that using SOC strategies reduces the subsequent need for a surviving orientation to work. In effect, it avoids difficulties by enabling the person to find his or her own way of dealing with the job.

H4: The use of SOC strategies is positively related to thriving at work.

H5: The use of SOC strategies is negatively related to surviving at work.

\section{Use of SOC Strategies, Thriving and Surviving at Work as Mediators}

As discussed earlier, a number of studies have shown positive associations of HR practices and SOC strategies with high job performance in late career (e.g., Rudolph, 2016; Bajor \& Baltes, 2003). For example, in a study with UK public sector employees Kooij and colleagues (2013) reported that the positive relationship between developmental HR practices and job performance strengthens with age. In a systematic review and meta-analysis, Moghimi and colleagues (2017) found SOC strategy use at work to be positively related to both self-rated and non-self-rated job performance. Moreover, SOC strategy use at work mediated and moderated the relationships of person and contextual antecedents with job performance. Hence, we hypothesize that: 
H6: Use of SOC strategies mediates the relationship of availability of HR practices with job performance.

Further, research to date has consistently demonstrated that thriving at work is positively associated with overall job performance as well as with specific dimensions of job performance (e.g., extra-role performance) (Fritz et al., 2011; Spreitzer et al, 2010; Porath et al., 2012; Paterson et al., 2014). On the other hand, initial insights into the surviving at work construct suggest a negative relationship with high work performance (Taneva et al., 2016). Surviving reflects a tendency to try to avoid challenge and change. We therefore suggest that higher use of the surviving at work approach will lead to reduced job performance. For instance, employees who are over-focused on protecting their limited resources would be less likely (compared with those with more resources) to demonstrate task proactivity (see Griffin, Neal, \& Parker, 2007) and involve themselves in extra-role performance behaviors (see Lynch, Eisenberger, \& Armeli, 1999). Also, surviving employees would struggle to invest in their development in the workplace (e.g., by updating current skills), which may ultimately result in decreasing levels of in-role performance (see Lynch et al., 1999). Moreover, we already predicted that both availability of HR practices and use of SOC strategies are positively related to individuals' experiences of thriving (hypotheses H1 and H3) and negatively associated with employees' experiences of surviving at work (hypotheses H2 and H4). Therefore, we propose the following group of mediation hypotheses:

H7: Thriving at work mediates the relationship of availability of HR practices with job performance.

H8: Thriving at work mediates the relationship of use of SOC strategies with job performance.

H9: Surviving at work mediates the relationship of availability of HR practices with job performance. 
H10: Surviving at work mediates the relationship of use of SOC strategies with job performance.

The relationships outlined in the hypotheses above are combined and shown graphically in Figure 1.

\section{INSERT FIGURE 1 ABOUT HERE}

\section{Method}

\section{Participants and Procedure}

Two of the UK organizations (one from the health and one from the ICT sector) that participated in Study 1 also took part in Study 2. We recruited two more UK organizations (again, one from the health and one from the ICT sector). All organizations were large, with over 1000 employees. The two health organizations were public healthcare providers in different UK locations, while the ICT organizations were multinational companies. Overall, organizational characteristics were very similar to those of the UK employers described in Study 1. Invitations to participate in an online survey (previously piloted in a UK educational organization) were posted on the organizations' intranets, and were sent by email by their HR departments to all employees with an email address, but specifying that our target group was those aged 55 years and over. Potential participants were assured that their responses were confidential and that participation was voluntary. They were also promised general feedback about the findings. Those who volunteered provided their informed consent online, through the survey.

Between October 2014 and May 2015, we received over 1000 responses, 853 of which were valid (i.e. completed). Thus, the average for the sample survey completion rate was about $85 \%$ and slightly higher for the ICT compared with the health sector. We cannot report 
the survey response rate, because we do not have precise information about the number of potential respondents from our target group (i.e. those aged 55 years and over), reached by the information posted online and emailed by their organizations. Two-hundred-and-ninety of the valid responses came from the health sector, 563 were submitted by ICT employees. Older ICT workers may have felt more comfortable working with the online questionnaire than older health workers, some of whom may have felt insecure about using information technologies (e.g., Taneva et al., 2016).

The mean age for the whole sample was $57.85(\mathrm{SD}=2.85)$, with $58.50(\mathrm{SD}=3.34)$ for the health and $57.52(\mathrm{SD}=2.50)$ for the ICT sectors. About $76 \%$ of health employees were female, while about $78 \%$ of ICT employees were male. These results correspond to previously published information regarding gender patterns in both sectors (HOFSPEEM, 2013; Schwartz-Woelzl \& Healey, 2007). Further, the majority of respondents $(68.2 \%$ of the workers in the entire sample, $48 \%$ of health workers and $78 \%$ of ICT workers) had been in their organizations for more than 20 years, and only $1.8 \%$ had been working with their current employers for less than 3 years.

\section{Measures}

In order to measure the main study variables, we used modified versions of a number of established instruments as well as a newly developed measure based on our previous work (Taneva et al., 2016). All items are presented in Appendix I. The reliability coefficients of all measures range from about .6 (for elective selection) to over .9 (for task proactivity) with a mean score of .769 and are presented in Table 2, along with descriptive statistics and intercorrelations. 
Thriving at Work. Thriving at Work was assessed with an adapted version of Porath et al.'s (2012) instrument. We used the three highest loading items (out of five) for each of the two sub-dimensions of the construct: Vitality and Learning. Moreover, we combined the two sub-dimensions into a total Thriving at Work score. This is important, because as conceptualized by Spreitzer et al. $(2005 ; 2012)$ the meaning of thriving at work captures the simultaneous experiences of both vitality and learning. In line with this conceptualization, empirical studies published so far have treated Thriving at Work as a single factor variable (e.g., Porath et al., 2012; Paterson et al., 2014). Example items are "I see myself continuously improving" and "I have energy and spirit". Responses were recorded on a 7-point strongly disagree - strongly agree Likert scale.

Surviving at Work. In this paper Surviving at Work is viewed as protecting the status quo (see preceding discussion in the theoretical section). It was assessed with three items developed for this study, derived from the content analysis of interviews with older workers in 10 organizations (Taneva et al., 2016). The three items composing Surviving at Work are: "My purpose is now to maintain the status quo at work", "I am mostly interested to learn only the things that I need to know at work", and "My goal now is to keep interested in my work without going to the next level of stress". Responses were recorded on a 5-point strongly disagree - strongly agree scale.

Availability of HR Practices that are valued by older workers. The eight HR practices were selected based on the analysis in Study 1 (see Table 1) and were assessed with one item for each practice adapted where possible from the instrument introduced by Armstrong-Stassen $(2008 \mathrm{a}, \mathrm{b})$. A specific example is "Financial incentives to remain in the workforce instead of retiring”. Responses were recorded on a 5-point strongly disagree strongly agree scale. Scores on the eight items were considered to reflect a single composite an Availability of HR Practices construct. 
Use of SOC strategies. SOC behaviors were assessed using a modified version of the measure offered by Freund and Baltes (2002) adapted to a work context (see Zacher \& Frese, 2011; Zacher, Chan, Bakker \& Demerouti, 2015). Elective Selection, Loss-based Selection, Optimization, and Compensation were each measured with three items. Example items for these scales are: Elective Selection "I concentrate all my energy on few things"; Loss-based Selection "When I can't do something important as well as I used to, I think about my priorities and what exactly is important to me"; Optimization/Compensation "If something matters to me, I devote myself fully and completely to it"; and "When things don't go as well as they used to, I keep trying other ways until I can achieve the same result I used to." Respondents were asked to describe the degree of similarity between themselves and the behaviors described in a work context using a 4-point scale from "A little" to "Exactly".

We chose to work with four separate indices for each form of SOC strategy. Research to date has focused largely on overall SOC strategy use (see Moghimi et al., 2017). This approach has been criticized for neglecting the conceptual distinctions between the four SOC components. Further, it has been recommended that "researchers report all SOC component scores, an overall score, and their correlations with antecedents and outcomes" (p. 271, Monghimi et al., 2017). In response to this call, we view SOC strategy use at two levels (i.e. as four first order factors and a higher order factor).

Job Performance. We did not have access to organizational records of job performance. Hence, job performance was self-rated. This may be a reason for cautious interpretation given that self-rated and supervisor-rated performance appear to be correlated about 0.35 on average (Harris \& Schaubroeck, 1988). However, although modest, 0.35 indicates some agreement, and there is no guarantee that supervisor ratings are always a reliable benchmark. Further, employees' self-ratings on job performance may contribute in an important way to overall ratings of job performance (see Conway \& Huffcutt, 1997). Several 
recent studies demonstrated that subjective performance may be a valid measure in studies with similar samples and variables as those in our study (e.g., Bal \& De Lange, 2015). Also, in a meta-analysis, Moghimi et al. (2017) found similar positive associations between use of SOC strategies with both self-rated and objective performance. Thus, we believe that although subjectively measured in this study, job performance measures will still provide valid and reliable information.

We assessed three elements of job performance in order to obtain as complete a picture as possible of this aspect of successful aging at work (see Warr, 1993; Ng, T.W.H., \& Feldman, 2008). Analyses of the structure of job performance ratings have distinguished between performance of core tasks (sometimes called In-role Performance) and willingness to be helpful to others and the organization as a whole (referred to as Extra-role Performance or Citizenship) (e.g., Viswesvaran \& Ones, 2000; Lynch et al., 1999). More recently, increasing emphasis has been placed on proactive behavior as a key component of performance in an era requiring innovation and rapid organizational responses to changing circumstances (Griffin, Neal, \& Parker, 2007). In-role Performance and Extra-role Performance were measured using a modified version of Lynch et al.'s (1999) scales. Four items assessed In-role Performance, an example being "I fulfil the responsibilities specified in my job description." Four items tapped Extra-role Performance, an example being "I make constructive suggestions to improve the overall functioning of my work group". Task Proactivity concerns the extent to which the person seeks new and better ways of doing his or her work, and was assessed using three items developed by Griffin et al. (2007). One of these was "I initiate better ways of doing my core tasks". Responses were recorded on a 5-point strongly disagree - strongly agree scale.

Similarly to our approach to the use of SOC strategy described above, in the following analyses section we work with job performance at two levels. First, we analyze the 
relationships of each job performance aspect with Thriving and Surviving at Work (i.e. the focal constructs in this study). Second, when analyzing background information, we focus on Job Performance as a higher order (i.e. general) factor.

Control variables. We also introduced two control variables - industrial sector and tenure in the organization. Regarding tenure, there is some evidence that longer tenure is associated with increasing in-role and extra-role performance, though this levels off with very long tenure (Ng, T.W.H., \& Feldman, 2010). Workers' tenure in the organization was measured with a single item offering five choices: "less than 1 year", "more than 1 and up to 3 years", "more than 3 and up to 10 years", "more than 10 and up to 20 years", and "more than 20 years". Regarding industrial sector, Eskildsen, Kristensen, and Juhl (2004) found that while private companies put high emphasis on the systems dimension, excellence in public organizations was defined with a stronger focus on the people dimensions. Thus, driven by different attitudes toward excellence, the employees from the two sectors may differ in their performance self-evaluations. The industrial sector of each respondent was recorded automatically upon receipt of survey responses.

\section{Analyses and Results}

\section{Preliminary Analyses}

First, in order to evaluate the construct validity of the measures, we conducted a confirmatory factor analysis (CFA) for the item structure of each measure with MPlus, Version 6.12 (Muthén \& Muthén, 1998-2011). The model fit statistics resulting from these analyses are presented in Table 3 below.

INSERT TABLE 3 ABOUT HERE 
Overall, the CFA revealed acceptable model fit for all study measures. No items needed removing from any of the three measures capturing various aspects (Task Proactivity, In-role and Extra-role Performance) of job performance in order to achieve a good model fit. We tested two models associated with job performance - 1-factor vs. 3-factor. These tests demonstrated a poor fit for the 1-factor model and acceptable, significantly better $\left(\Delta \chi^{2}(6)=\right.$ $1150.816, \mathrm{p} .<.001)$ fit for the 3-factor solution. Thus, we considered job performance a 3factor measure in our subsequent structural models. In a similar fashion, we tested two models (1-factor vs. 4-factor) associated with the use of selection, optimization and compensation strategies. All 12 items of the four SOC subscales (Elective Selection, Lossbased Selection, Optimization and Compensation) were retained. Given the significant improvement of the model fit for the 4-factor solution $\left(\Delta \chi^{2}(6)=625.109, \mathrm{p} .<.001\right)$, we chose this model for our further analyses.

Initially, for thriving at work we tested two models (1-factor and 2-factor) including all 10 items of the original measure. Neither of the models demonstrated a good enough fit. In order to improve the model fit, we removed the four items (two per subscale) that loaded with the lowest loadings (see Appendix I). The item removals were both theoretically and statistically justified (e.g., subsequent Chi Square tests for differences showed that both 1and the 2-factor models using six items had a significantly better model fit than the 2-factor model using all ten items (resp. $\Delta \chi^{2}(27)=331.6$, p. $<.001$ and $\Delta \chi^{2}(26)=330.832$, p. $<$ $.001)$. There was no significant difference between the fit of these two models $\left(\Delta \chi^{2}(1)=\right.$ $1.56, \mathrm{~ns})$. To be consistent with existing analyses of its construct validity, we decided to view Thriving at Work as a unidimensional (i.e. 1-factor) construct in our further analyses.

Surviving at work includes only 3 items and, thus, is the shortest measure in our study. In order to produce fit statistics for this just-identified CFA, the error terms for each of the three items was set at .3. The practice of fixing the error variance to a specified value is described 
in detail by Bentler \& Chou (1987). Consequently, we considered the fit of this model acceptable (see Table 3) and retained all items.

We conducted a CFA for the measure capturing the perceived availability of the $8 \mathrm{HR}$ practices identified in Study 1 (see Table 1). The initially tested 1-factor model did not have an acceptable fit. For this reason, we applied a modification procedure (Jöreskog \& Sörbom, 1983; Steiger, 1990). Several large modification indices were suggested, involving the correlation of several pairs of related items within the HR construct: a.) "Training to learn new skills" with "Training to update current skills" (M.I. $=360.735$, Standardized EPC = $3.029)$, b.) "Financial incentives to remain in the workplace instead of retirement" with "Recognition of the significant role mature employees can play" (M.I. $=186.817$, Standardized EPC =.478), and c.) Useful feedback from supervisor/manager" with "Recognition of the significant role mature employees can play" (M.I. = 74.147, Standardized $\mathrm{EPC}=.307) . \quad$ Given the significant improvement in model fit $(\Delta \chi 2(3)=396.873, \mathrm{p} .<$ .001 ), we included these correlations in the final model. Theoretically, both training for updating current skills and gaining new knowledge imply orientation toward learning. Useful feedback from supervisor as well as the availability of financial incentives to remain in the workplace may be (and, indeed, were in Study 1) seen by older workers as a sign of recognition and respect. Hence, the correlations between the HR items outlined above are meaningful.

Taking all variables together, we used CFA and Chi-Square difference test to evaluate three alternative measurement models. The fit statistics are presented in Table 4. Overall, the CFA and the two Chi-Square difference tests $\left(\Delta \chi^{2}(10)=4574.83\right.$, p. $<.001$ for 1 -factor vs. 5-factor model, and $\Delta \chi^{2}(35)=1985.919$, p. $<.001$ for 5-factor vs. 10-factor model) supported the use of the 10 -factor solution. Based on the 10 distinct constructs in this model (HR Practices, Elective Selection, Loss-based Selection, Optimization, Compensation, 
Thriving at Work, Surviving at Work, Task Proactivity, In-role Performance, and Extra-role Performance) scale scores were correlated. The factor loadings and the R-square statistics of the items of this model are presented in Appendix I.

\section{INSERT TABLE 4 ABOUT HERE}

Finally, we tested the 10 -factor model for common method bias following the approach described by Williams \& McGonagle (2016). Because we did not have the opportunity to use a marker variable (i.e. a measure of a construct that is not related to the rest of the constructs in our study) or a direct measurement for method effects (e.g., a social desirability scale), we chose the unmeasured latent method construct (ULMC) approach. All indicators of the 10 latent variables loaded onto a common factor, labelled Common Method Variance Factor (CMVF). Thus, there were 11 latent variables in total. The variances of the latent variables were set at 1 and the correlations between the ULMC and the latent variables were set at 0 . The fit statistics for the 11-factor model with CMFV are RMSEA $=.046,90 \%$ CI $[.043$, $.048], \mathrm{CFI}=.927, \mathrm{TLI}=.917, \chi^{2}(650)=1799.850, \mathrm{SRMR}=.059$. Then, the 11 -factor model was tested against a model without the common factor, i.e. a 10-factor model (RMSEA $=$ $.046,90 \% \mathrm{CI}[.043, .048], \mathrm{CFI}=.927, \mathrm{TLI}=.917, \chi 2(651)=1800.881, \mathrm{SRMR}=.059)$ and the fit statistics of the models with and without the CMVF were compared using a ChiSquare difference test. The model fit did not degrade significantly when the common factor was removed $\left(\Delta \chi^{2}(1)=1.031, \mathrm{~ns}\right)$. Hence, there is not significant common method variance. Thus, although all of our measures are self-reported, we did not find evidence of common method bias that could affect the validity of our results.

\section{Testing the Research Hypotheses}


The descriptive statistics of the study variables are presented in Table 2. Overall, respondents tended to agree with the thriving items and disagree with the surviving ones, suggesting in general a growth-oriented experience of work. Responses to the items of the three components of job performance suggested a fairly but not extremely positive self-view of effectiveness at work. The highest average scores were associated with in-role performance, followed by extra-role performance, and then task pro-activity. Responses to the items of each of the four clusters of SOC strategies indicated an overall moderate use of these strategies with the optimization strategies being used most. As anticipated, thriving and surviving were significantly and negatively correlated. Further, thriving was moderately positively correlated, and surviving weakly negatively correlated, with each of the components of job performance. Overall, the use of the four SOC strategies and the perceived availability of HR practices were positively correlated with the three components of job performance and with thriving. Surviving was negatively correlated with availability of HR practices and with thriving, as well as with the use of the optimization strategy. Health employees tended to score slightly higher than ICT employees in their thriving, in-role and extra-role performance. Employees with longer organizational tenure tended to demonstrate slightly higher levels of surviving and lower in-role performance.

Following the preliminary analyses described in the previous section, our hypothesized structural model (see Figure 1) is composed of 10 first order latent variables (see Table 3), as well as two higher order latent variables - Overall Use of SOC strategies and Overall Job Performance (Cattell, 1978) - which were assessed in conjunction with (not instead of) their components. Overall Use of SOC strategies involves all four types of proactive behaviours, and is included here in recognition of the theory and research that has employed an overall measure of SOC strategy use rather than breaking it down into its four components (Moghimi et al., 2017). As Zacher and Frese (2011, p. 309) have pointed out, theorists have construed 
SOC as a "synchronized ensemble of strategies" that can be considered as a whole. However, they also acknowledge that future research might investigate potentially different effects of individual SOC strategies. We take both approaches. Regarding Overall Job Performance, Viswesvaran and Ones (2000) amongst others have concluded that as well as specific components of job performance, there is a clear general factor in ratings. Again, we seek to examine both the general and the specific.

This hypothesized model was estimated using a maximum likelihood (ML) algorithm and 1,000 bootstrapped samples to accurately estimate indirect effects (see Preacher \& Hayes, 2008). The diagram in Appendix II depicts the standardized path estimates and error variances for each of the endogenous variables, and all significant effects are presented graphically in Figure 2 below.

\section{INSERT FIGURE 2 ABOUT HERE}

Analysis confirmed a significant effect of industrial sector on job performance $(\beta=$ $.13, \mathrm{p}<.05$ ). Health sector employees scored (slightly) higher on average than ICT employees on job performance. Organizational tenure did not have a significant effect on job performance.

According to Hypothesis 1, availability of HR practices is expected to be positively related to the overall use of SOC strategies. This prediction was supported $(\beta=.17, \mathrm{p}<.01)$. In line with Hypotheses 2 and 3, we found that availability of HR practices is positively related to thriving at work $(\beta=.46, \mathrm{p}<.001)$ and negatively associated with surviving at work $(\beta=-.26, p<.001)$. In addition, it was hypothesized that the use of SOC strategies would be positively related to thriving at work (Hypothesis 4), and negatively related to surviving at work (Hypothesis 5). Both hypotheses were partially confirmed as we found a 
significant positive relationship only between the optimization strategies and thriving at work $(\beta=.34, \mathrm{p}<.001)$ and a significant negative relationship only between the optimization strategies and surviving at work $(\beta=-.27, \mathrm{p}<.01)$. The anticipated significant relationships of the elective selection, loss-based selection and compensation behaviours with both thriving and surviving at work were not confirmed.

Regarding the predicted indirect effects, all our hypotheses (6-10) were fully or partly supported. In line with Hypothesis 6, we found a significant indirect effect of available HR practices on overall job performance through overall use of SOC strategies $(\beta=.09, \mathrm{SE}=.03$, $\mathrm{p}<.001,95 \%$ CI $[.045, .136])$. Notably, thriving at work mediated the relationship between available HR practices and each job performance dimension. More specifically, there was a significant indirect effect of available HR practices on task proactivity through thriving at work $(\beta=.12, \mathrm{SE}=.02, \mathrm{p}<.001,95 \% \mathrm{CI}[.07, .165])$ and significant indirect effects of available HR practices, through thriving at work, on both in-role $(\beta=.146, \mathrm{SE}=.02, \mathrm{p}<$ $.001,95 \%$ CI $[.102, .183])$ and extra-role performance $(\beta=.097, \mathrm{SE}=.02, \mathrm{p}<.001,95 \% \mathrm{CI}$ $[.045, .149])$. Hence, Hypothesis 7 was fully supported. In partial support of Hypothesis 8 thriving at work mediated the relationship between the optimization strategies (but not any of the other three SOC dimensions) and each job performance aspect. There was a significant indirect effect via thriving at work between use of optimization strategies and task proactivity $(\beta=.087, \mathrm{SE}=.02, \mathrm{p}<.001,95 \% \mathrm{CI}[.04, .133])$, in-role performance $(\beta=.11, \mathrm{SE}=.02, \mathrm{p}<$ $.001,95 \% \mathrm{CI}[.052, .158])$, and extra-role performance $(\beta=.071, \mathrm{SE}=.02, \mathrm{p}<.001,95 \% \mathrm{CI}$ $[.023, .119])$

Our prediction of mediation effects of surviving at work on the relationship between available HR practices and the three job performance dimensions (Hypothesis 9) was partly supported as we found a significant indirect effect of available HR practices via surviving at work only on extra-role performance $(\beta=.05, \mathrm{SE}=.01, \mathrm{p}<.001,95 \%$ CI $[.019, .077])$. 
Lastly, we identified a significant indirect effect of the use of optimization strategies on extra-role performance through surviving at work $(\beta=.049, \mathrm{SE}=.02, \mathrm{p}<.001,95 \% \mathrm{CI}$ $[.023, .119])$. There were no significant indirect effects via surviving at work associated with any of the other three SOC strategies (elective selection, loss-based selection and compensation) and the remaining two components of job performance (task proactivity and in-role performance). Thus, Hypothesis 10 was only partly confirmed.

\section{General Discussion}

\section{Contributions}

The purpose of this paper was to extend the knowledge of successful aging at work by introducing and testing a new conceptual model. The model is a unique intersection of lifespan, human resource management and positive organizational behavior literatures. We have reported two studies, one qualitative, one quantitative, concerning how human resource and individual behavioral strategies can play a part in the successful aging process among workers aged 55 and over. Like Zacher (2015a), we view successful aging at work as a multifaceted phenomenon with both personal and contextual antecedents, and we respond to his call for research on age-related mediators in the successful aging process. We shed light on both well-being (thriving and surviving) and performance elements of successful aging in the work context. We combine elements of well-being and effective performance in one model rather than treating them as parallel but separate outcomes. Drawing on past work (e.g., Armstrong-Stassen, 2008b; Kooij et al., 2014), we identify a set of eight HR practices that are especially salient to older workers. Also, we explore the role of SOC strategies use in successful aging at work in a dual way - as antecedents of thriving/surviving at work and as mediators of the relationship of HR practices with job performance. To our knowledge, this is 
the first study in the context of older workers to position SOC strategies and thriving as mediators of the effects of HR practices on performance (Moghimi et al., 2017), to assess three conceptually distinct elements of job performance, and to consider SOC strategies and job performance both as general constructs and in terms of their specific components. We also introduce a new construct, surviving at work, which reflects an individual's attempt to preserve the status quo at work.

We find (Study 1) from interviews with 37 healthcare and ICT sector workers and 10 HR managers in the UK and Bulgaria that a range of HR practices are salient to older workers. These are not confined to any one of the categories identified by Kooij et al. (2014) though they are skewed toward the developmental and they often depend more upon informal arrangements with immediate supervisors than upon official HR policies (see Martin et al., 2016; Bal, 2015). In Study 2 we test a structural model with 853 workers based in the UK from the same two sectors. We find that the perceived availability of HR practices is related to overall job performance via use of SOC strategies and to individual components of job performance via thriving at work and (to a lesser extent) via low use of surviving strategies at work. Optimization has additional relationships over and above those of overall SOC use, and, like HR practices, is linked to the components of job performance via thriving and to a lesser extent via surviving.

Our findings support suggestions that successful aging at work is influenced by a range of factors, both personal and organizational (Kooij, 2015a; Zacher, 2015a). Specifically, we extend other work on the importance of HR practices (e.g., Kooij et al., 2013; Bal \& De Lange, 2015) and SOC strategies (Bajor \& Baltes, 2003; Rudolph, 2016; Moghimi et al., 2017) for psychological outcomes at work by investigating them both together in a large sample of older workers and demonstrating that they both play a part in thriving and work performance, over and above each other, as well as SOC strategies being a mediator of the 
effects of HR practices on self-rated job performance. By positioning thriving as a mediator, we offer an explanation and demonstration of how effective human resource management and self-management can foster growth and energy in late career, and thereby work effectiveness which includes not only core duties but also good citizenship and proactivity.

The role of SOC strategies for successful aging at work. Despite the mediating role of thriving, it is notable that the use of SOC strategies also had a strong relationship with overall self-rated job performance. This indicates that use of such strategies has performance benefits that do not depend upon a conscious sense of vitality and learning. In a sense, this is not surprising because SOC strategies are behaviors designed to deploy personal resources to best advantage (Baltes and Baltes, 1990) in order to achieve personal goals. The use of SOC behaviors does not necessarily require boosts in learning or energy in order to achieve good performance. Indeed, SOC strategies are more about making the most of existing energy and prior learning. This is consistent with our previous finding (Taneva et al., 2016), that older workers regarded SOC strategies as a natural consequence of their accumulated expertise, and not as a way of compensating for decline. The strong connection between use of SOC strategies and performance is consistent with several previous studies (e.g., Weigl, Muller, Hornung, Zacher \& Anderer, 2013), but its strength is perhaps surprising given that Zacher and Frese (2011) found stronger effects of SOC amongst people in low complexity jobs. Many respondents in Study 2 had relatively complex jobs.

However, use of the SOC strategy optimization demonstrated additional relationships over and above those of SOC strategies as a whole. It was positively associated with thriving and negatively associated with surviving, and via those variables had indirect effects on job performance. This prominence of optimization (as opposed to other components of SOC) in relationships with other variables is somewhat unusual (c.f. Bal et al., 2013; Weigl et al., 2013; Yeung \& Fung, 2009), though respondents in Ng, E. S. W., and Law's (2014) 
qualitative study mentioned using optimization strategies quite a lot, and in Zacher, Chan, Bakker \& Demerouti (2015) optimization was associated with work engagement. More than the other components of SOC, optimization is aimed at achieving higher levels of functioning rather than compensating for losses, and potentially includes learning new skills (Bajor \& Baltes, 2003). It is therefore logical that it should connect with thriving. Its prominence in this study also acts as a reminder that even amongst older workers, the role of SOC is not confined to compensating for losses.

The role of organizational practices for successful aging at work. The set of HR practices that we identified as being salient to older workers in Study 1 and operationalized in Study 2 is notable for its diversity in terms of past classifications of types of HR practice (Kooij et al., 2014). Their strong link with thriving in Study 2 suggests that their effect is developmental. Because it is a package of eight, we cannot be specific about the role of any single HR practice. However, it raises the possibility that practices that at first glance seem to promote either maintenance of current functioning or compensation for declining capacity, may also foster development of new skills or the refreshment, reinvigoration or use of existing ones (Kooij et al., 2013; 2014). For example, additional leave may foster vitality, or even learning, depending on what the person does with that leave. Financial incentives to keep working might help to prevent withdrawal from an arena which offers possibilities not only for material gain but also for growth (Kim \& Feldman, 2000). The significant albeit modest relationship between HR practices and overall use of SOC strategies suggests that as well as influencing the design of jobs and organizational culture (Boehm et al., 2014), welldesigned HR can also give people scope to exert control over how they do their job. The absence of direct relationships between availability of HR practices and job performance (unlike SOC strategies) shows that HR is an enabler of behaviors and well-being that in turn contribute to performance. 
Some of the themes identified in Study 1 are consistent with the assertion by SES theory (Carstensen et al., 1999; Kooij et al., 2011; Thrasher et al., 2016) that late-career workers tend to focus on short-term goals which manifests as a desire for relational depth with existing contacts and affirmation of self-concept. This is particularly the case for the themes "recognition of the significant role mature workers can play" and "challenging and meaningful tasks/assignments". Indeed, other research also suggests that recognition/appreciation is important to late career workers' continued engagement in the workplace (Armstrong-Stassen, 2008a,b). Thriving is arguably a manifestation of a long-term (along with shorter-term) time perspective, and surviving clearly militates toward a shortterm perspective. In this study HR practices foster thriving and reduce surviving, so even if the HR practices themselves tend to reflect the priorities of older workers with a short-term time perspective, they may help to create the conditions necessary for a longer-term time perspective, perhaps through giving older workers a sense of psychological safety that allows them to explore and develop. A longer-term time perspective, with attendant focus on opportunities, has been suggested as a criterion of successful aging (Zacher \& Frese, 2011).

Because this is a cross-sectional study and also we do not know the population trend over time in performance (Zacher, 2015a), we cannot assert that the variables measured here improve work performance in an absolute sense. However, our findings do suggest that opportunities for successful aging, defined as a more positive trajectory than the average (Zacher, 2015a), are likely to be improved by well-chosen HR practices and effective personal use of selection, optimization and compensation (SOC) behavioral strategies. As we noted in our previous work (Taneva et al., 2016), it seems that these strategies are not used only, or even mainly, as a way of compensating for losses. Instead, they reflect wise behavioral choices that can stimulate growth. This adds weight to work in psychology and 
organizational behavior which takes a positive view of human potential (Spreitzer \& Sutcliffe, 2007).

Thriving, surviving and job performance. This study provides further evidence for the significance of the thriving construct as a predictor of positive outcomes at work. To our knowledge, this is the first study of thriving to focus specifically on late career workers. It is encouraging to see not only that they reported experiencing a reasonably high amount of thriving, but also that thriving fostered effective job performance. Porath et al. (2012) found a positive relationship between thriving and a short measure of job performance that reflected mainly in-role performance. In the present study we replicate that, and also find that thriving appears to contribute to extra-role performance and proactivity. This makes sense because learning gives a person the know-how to be proactive and vitality helps a person have enough energy to contribute beyond their core job tasks. In contrast, surviving does not undermine inrole performance, perhaps because that is exactly what survival strategies aim to protect. By the same token, proactivity and extra-role performance do appear to be undermined by use of surviving at work.

The concept of surviving reflects a significant and much less positive potential element of aging at work. However, our findings suggest that it plays a weaker negative role than thriving's positive role in successful aging at work. As we expected, surviving measured by the three-item scale was significantly negatively correlated with thriving, the three components of work performance and availability of HR practices. However, most of these relationships were quite small and the connections with job performance also small and significant only for extra-role performance. This suggests that what we interpret as defensive behavior is not as damaging as might be expected, once thriving is taken into account. Perhaps in some work settings older workers are (as some said in the Study 1 interviews) left in something of a cul-de-sac where they are labeled as "late career workers" by managers 
(Loretto \& White, 2006) and may indeed label themselves in that way (Desmette \& Gaillard, 2008). This could mean that expectations of their performance (including their own expectations) are modest. In these circumstances, there may be ways of using surviving strategies to achieve sustainable person-environment fit, and therefore at least moderately successful aging in the form discussed by Kooij (2015a), that do not involve growth, but is mostly associated with maintenance.

\section{Implications for Practice}

Our Study 1 findings can help HR managers be aware that older workers may not see the training and development opportunities available as being relevant to them, so it is important not to "blame the victim" if take-up of training by older workers is disappointing. It is also important to remember that informal day to day feedback from, and relationships with, immediate bosses carry more weight than formal performance appraisal processes (Buckingham \& Goodall, 2015). Not only do these informal processes let older workers know how they are doing, they also allow negotiation of roles and responsibilities, and an opportunity for older workers to craft their contribution (Kooij, 2015b; Kooij et al., 2016) and feel they are being trusted and respected (Bal, 2015; Martin et al., 2016). Furthermore, such arrangements may increase work flexibility and help older workers deal effectively with work-family balance (Thrasher et al., 2016). It is therefore important that supervisors of older workers are made aware of these dynamics, and that they know how much room for maneuver the organization allows in making informal arrangements (e.g., i-deals, see Bal., 2015). Finally, HR managers might consider whether they are thinking sufficiently creatively about retirement pathways and preparation, and opportunities for post-retirement work. This seems to be an area of missed opportunity for encouraging not only a withdrawal from work, but also opportunities to thrive and grow in late career. 
Our Study 2 findings reinforce the significance of HR practices for the work performance and continued vitality, development and psychological well-being of late-career workers. They also make a strong case for both HR managers and older workers themselves to pay attention to using SOC strategies at work. Training or self-study to become familiar with the core concepts, and workshops or guidance about how to apply them to one's specific late career work situation, are likely to have significant benefits. There may be a case for developing organization-specific training materials. Müller, Heiden, Herbig, Poppe, \& Angerer (2016) have done that in an intervention study with nurses, and although the effects were limited, this may be a good resource. Given its role in this study, special attention might be given to optimization strategies. Further, it might be useful to develop older workers' awareness of the danger signs of surviving. For some, surviving might feel like what naturally happens in late career. However, given its negative correlates, it is important to identify when one is falling into that way of thinking and try to find ways (probably in consultation with line managers) how to (i) reduce it and (ii) replace it with elements of thriving.

\section{Limitations and Suggestions for Future Research}

Some theoretical and empirical work has argued that SOC strategies and certain HR practices become more important as workers age (e.g., Baltes \& Baltes, 1990; Kooij et al., 2013). The present studies are consistent with that, but because this research focused on late career, nearly all of our participants were in their mid/late fifties or early sixties. This very narrow age range meant that we could not meaningfully test age as a moderator or examine whether the same results applied to younger respondents. Future research could extend the age range to see what if anything about our findings is age-specific. However, even if the findings were the same, they would not invalidate the message that, for older workers, successful aging in the form of thriving and performance can be bolstered by use of certain 
HR practices and SOC strategies. Future research could test the replicability of our findings in different populations and sub-populations. For example, in high uncertainty avoiding cultures, surviving might both me more common and less negative in its effects because people are expected, and expect themselves, to enact roles in a narrowly defined, unchanging way (c.f. Staufenbiel \& Konig, 2010). Gender may be another relevant factor. If late career is more likely to be a time of flourishing for women than for men as some suggest (e.g., O’Neil \& Bilimoria, 2005), thriving may play an even more prominent role for women than for men. Furthermore, we found significant effects of industrial sector on job performance. Future research could consider examining the role of industrial sector as a moderator in the successful aging at work process.

Research has demonstrated that considering the interactions between the subcomponents of a construct may provide valuable information about the relationships of this construct with other constructs (see Zacher et al., 2015). In Study 2 we found that, when considered together, the eight HR practices from Study 1 affect job performance through SOC strategy use, thriving and surviving at work in specific ways. However, we did not explore the effects of the interactions between these practices on work outcomes. It may be useful to investigate how these elements interact with each other and the effects of such interactions on work outcomes.

We acknowledge that as well as our respondents being homogeneous in age, the studies are cross-sectional. Although we proposed and argued for a causal configuration of the variables in Study 2, the statistical analyses cannot prove that this is correct, only that the data are, in some respects at least, consistent with our proposal. Furthermore, the data are all selfreport and the data in Study 2 (vs Study 1) come from a single source. As well as raising questions about the accuracy of perceptions of the key variables, especially perhaps availability of HR practices, this might have artificially inflated the associations between 
variables in Study 2. However, our check for common method variance suggested that this was not a major problem. Self-rated work performance might be problematic in terms of its accuracy, though it is very common to assess performance in this way (Moghimi et al., 2017; Ng, T.W.H., \& Feldman, 2008). Future researchers wishing to assess the performance aspect of successful aging could consider obtaining multi-source data so that, for example, a person's self-reported thriving is assessed alongside supervisor ratings of performance. Equally important will be longitudinal data which give a better opportunity to discover how these processes unfold over time.

Unlike the measure of thriving, our measure of surviving was home-grown and not empirically validated before being employed in this research. However, the items were derived from things interviewees said to us, and in our view, have construct validity as a kind of "maintenance gone bad," likely reflecting compensation for losses and a defensive desire to stick to the core elements of the job and to do them in well-established (and possibly now dysfunctional) ways. Future research might seek to validate and if necessary refine the measure as Porath and colleagues (2012) have done for thriving, in order (hopefully) to establish its place in the web of work attitude variables. 


\section{References}

Abraham, J. D., \& Hansson, R. O. (1995). Successful aging at work: an applied study of selection, optimization, and compensation through impression management. The Journals of Gerontology. Series B. Psychological Sciences and Social Sciences, 50(2), 94-103.

Armstrong-Stassen, M., \& Templer, A. (2005). Adapting training for older employees: The Canadian response to an aging workforce. Journal of Management Development, $24(1), 57-67$.

Armstrong-Stassen, M. (2008a). Organisational practices and the postretirement employment experience of older workers. Human Resource Management Journal, 18(1), 36-53.

Armstrong-Stassen, M. (2008b). Human resource practices for mature workers -- And why aren't employers using them? Asia Pacific Journal of Human Resources, 46(3), 334 352.

Bajor, J. K., \& Baltes, B. B. (2003). The relationship between selection optimization with compensation, conscientiousness, motivation, and performance. Journal of Vocational Behavior, 63(3), 347-367.

Bal, P. (2015). Sustainable careers: enabling older workers to continue working through individualized work arrangements. In: De Vos, A. and Van der Heijden, B., eds. Handbook of Research on Sustainable Careers. Cheltenham: Edward Elgar, pp. 304318.

Bal, P.M., \& De Lange, A.H. (2015). From flexibility human resource management to employee engagement and perceived job performance across the lifespan: A multisample study. Journal of Occupational and Organizational Psychology, 88(1), 126-154. 
Bal, P. M., \& Dorenbosch, L. (2014). Age-related differences in the relationship between individualised HRM and organisational performance: a large-scale employer survey. Human Resource Management Journal, 25(1), 1-21.

Bal, P. M., Kooij, D. T. A. M., \& De Jong, S. B. (2013). How do developmental and accommodative HR enhance employee engagement and commitment? The role of psychological contract and SOC strategies. Journal of Management Studies, 50(4), $545-572$.

Baltes, P. B., \& Baltes, M. M. (1990). Psychological perspectives on successful aging: The model of selective optimization with compensation. In P. B. Baltes \& M. M. Baltes. (Eds.), Successful aging: Perspectives from the behavioral sciences (pp, 1-34). New York: Cambridge University Press.

Barnes, H., Smeaton, D., \& Taylor, R. (2009). An aging workforce: The employer's perspective. Institute for Employment Studies. http://www.employment$\underline{\text { studies.co.uk/resource/ageing-workforce-employers-perspective }}$

Bentler, P. M., \& Chou, C. P. (1987). Practical issues in structural modeling. Sociological Methods \& Research, 16(1), 78-117.

Besen, E., \& McNamara, T. (2009). Attitudes toward workers of different career stages. State Issue Brief, Chestnut Hill, Mass.: Sloan Center on Aging \& Work at Boston College. http://hdl.handle.net/2345/3596

Boehm, S. A., Kunze, F., \& Bruch, H. (2014). Spotlight on age-diversity climate: The impact of age-inclusive HR practices on firm-level outcomes. Personnel Psychology, 67(3), 667-704.

Bohlinger, S., \& van Loo, J. (2010). Lifelong learning for ageing workers to sustain employability and develop personality. In CEDEFOP: Working and ageing: emerging 
theories and empirical perspectives (pp. 28-57), Luxembourg: Publications Office of the European Union.

Braun, V., \& Clarke, V. (2006). Using thematic analysis in psychology, Qualitative Research in Psychology, 3(2), 77-10.

Buckingham, M., \& Goodall, A. (2015). Reinventing performance management. Harvard Business Review, 93(4), 40-50.

Campbell, J. L., Quincy, C., Osserman, J., \& Perderson, O. K. (2013). Coding in-depth semi-structured interviews: Problems of utilization and intercoder reliability and agreement, Sociological Methods and Research, 42(3), 294-320.

Carmeli, A, \& Spreitzer, G. (2009). Trust, connectivity, and thriving: Implications for innovative work behavior. Journal of Creative Behavior, 43(3), 169-191.

Carstensen, L. L. (1992). Social and emotional patterns in adulthood: Support for socioemotional selectivity theory. Psychology and Aging, 7(3), 331-338.

Carstensen, L. L., Turan, B., Scheibe, S., Ram, N., Ersner-Hershfield, H., Samanez-Larkin G.R., Brooks, K.P., \& Nesselroade, J.R. (2011). Emotional experience improves with age: evidence based on over 10 years of experience sampling. Psychology and Aging, 26(1), 21-33.

Carstensen, L. L., Isaacowitz, D. M.; \& Charles, S. T. (1999). Taking time seriously: A theory of socioemotional selectivity, American Psychologist, 54(3), 165-181.

Cattell, R. B. (1978). The scientific use of factor analysis in Behavioral and Life Sciences. New York: Plenum.

Conway, J. M. and Huffcutt, A. I. (1997). Psychometric properties of multisource performance ratings: A meta-analysis of subordinate, supervisor, peer, and self-ratings. Human Performance, 10(4), 331-360 
Denscombe, M. (2007). The good research guide for small scale social research projects. (3rd Ed) Berkshire: Open University Press.

Desmette, D., \& Gaillard, M. (2008). When a "worker" becomes an "older worker" The effects of age-related social identity on attitudes toward retirement and work. Career Development International, 13(2), 168-185

Ebner, N. C., Freund, A. M., \& Baltes, P. B. (2006). Developmental changes in personal goal orientation from young to late adulthood: From striving for gains to maintenance and prevention of losses. Psychology and Aging, 21(4), 664-678.

EEO Review (2012). Employment policies to promote active aging. Retrieved from http://www.eu-employment-observatory.net/resources/reviews/ EEOReviewActiveAging-2012-published-FINAL.pdf

Eskildsen, J. K., Kristensen, K., and Juhl, H. J. (2004). Private versus public sector excellence, The TQM Magazine, 16(1), 50-56.

Eurofound (2012). Sustainable work and the ageing workforce. http://www.eurofound.europa.eu/publications/report/2012/working-conditions-socialpolicies/sustainable-work-and-the-ageing-workforce

Franklin, N. C., \& Tate, C. A. (2009). Lifestyle and successful aging: An overview. American Journal of Lifestyle Medicine, 3(1), 6-11.

Freund, A. M., \& Baltes, P. B. (2002). Life-management strategies of selection, optimization and compensation: Measurement by self-report and construct validity. Journal of Personality and Social Psychology, 82(4), 642-662.

Fritz, C., Lam, C. F., \& Spreitzer, G. M. (2011). It's the little things that matter: An examination of knowledge workers' energy management. Academy of Management Perspectives, 25(3), 28-39. 
Griffin, M. A., Neal, A., \& Parker, S.K. (2007). A new model of work role performance: positive behavior in uncertain and interdependent contexts, Academy of Management Journal, 50(2), 327-347.

Hansson, R. O., DeKoek, P. D., Neece, W. M., \& Patterson, D.W. (1997). Successful aging at work: Annual review, 1992-1996: The older worker and transitions to retirement. Journal of Vocational Behavior, 51(2), 202-233.

Harris, M. M., \& Schaubroeck, J. (1988). A meta $\square$ analysis of self $\square$ supervisor, self $\square$ peer, and peer $\square$ supervisor ratings. Personnel Psychology, 41(1), 43-62.

HelpAge Internatonal (2015). Global AgeWatch Index 2015 Insight report. Retrieved 25 February 2017 from http://www.helpage.org/global-agewatch/reports/globalagewatch-index-2015-insight-report-summary-and-methodology/

HOSPEEM (2013). EPSU-HOSPEEM Guidelines \& good practice examples "Ageing Workforce Healthcare Sector.” Retrieved from http://www.epsu.org/IMG/pdf/EPSUHOSPEEM-GGP-AW-FINAL-04-12-13-EN.pdf

Jöreskog, K. G., \& Sörbom, D. (1983). LISREL VI: Analysis of linear structural relationships by the method of maximum likelihood. Chicago: International Educational Services.

Kanfer, R., \& Ackerman, P. L. (2004). Aging, adult development, and work motivation. Academy of Management Review, 29(3), 440-458.

Kanfer, R., Beier, M. E., \& Ackerman, P. L. (2013). Goals and motivation related to work in later adulthood: An organizing framework. European Journal of Work and Organizational Psychology, 22(3), 253-264.

Kim, S., \& Feldman, D. C. (2000). Working in retirement: The antecedents of bridge employment and its consequences for quality of life in retirement. Academy of Management Journal, 43(6), 1195-1210. 
King, N. (2004a). Using interviews in qualitative research. In C. Cassell \& G. Symon (Eds.), Essential Guide to Qualitative Methods in Organizational Research. London: Sage.

King, N. (2004b). Using templates in the thematic analysis of text. In C. Cassell \& G. Symon (Eds.), Essential Guide to Qualitative Methods in Organizational Research. London: Sage.

Kooij, D. T. A. M., Tims, M., \& Kanfer, R. (2016). Successful aging at work: The role of job crafting. In P. M. Bal, D. T. A. M. Kooij, \& D. M. Rousseau (Eds.), Aging Workers and the Employee-Employer Relationship. (pp. 145-161), Springer International Publishing.

Kooij, D. T. A. M. (2015a). Successful aging at work: The active role of employees. Work, Aging and Retirement, 1(4), 309-319.

Kooij, D. T. A. M. (2015b). Clarifying and discussing successful aging at work and the active role of employees. Work, Aging and Retirement, 1(4), 334-339.

Kooij, D. T. A. M., De Lange, A. H., Jansen, P. G. W., Kanfer, R., \& Dikkers, J. S. E. (2011). Age and work-related motives: Results of a meta-analysis. Journal of Organizational Behavior, 32(2), 197-225.

Kooij, D. T. A. M., Guest, D. E., Clinton, M., Knight, T., Jansen, P. G. W., \& Dikkers, J. S. E. (2013). How the impact of HR practices on employee well-being and performance changes with age. Human Resource Management Journal, 23(1), 18-35.

Kooij, D. T. A. M., Jansen, P. G. W., Dikkers, J. S. E., \& De Lange, A. H. (2014). Managing aging workers: a mixed methods study on bundles of HR practices for aging workers. The International Journal of Human Resource Management, 25(15), 2192-2212.

Kuvaas, B., \& Dysvik, A. (2009). Perceived investment in employee development, intrinsic motivation and work performance. Human Resource Management Journal. 19(3), 217-236. 
Loretto, W., \& White, P. (2006). Employers' attitudes, practices and policies toward older workers. Human Resource Management Journal, 16(3), 313-330.

Lynch, P. D., Eisenberger, R., \& Armeli, S. (1999). Perceived organizational support: Inferior-versus-superior performance by wary employees. Journal of Applied Psychology, 84(4), 467-483.

Martin, R., Thomas, G., Guillaume, Y., Lee, A. \& Epitropaki, O. (2016). Leader-member exchange (LMX) and performance. A meta-analytic review. Personnel Psychology, $69,67-121$.

Madill, A., Jordan, A., \& Shirley, C. (2000). Objectivity and reliability in qualitative analysis: Realist, contextualist and radical constructionist epistemologies. British Journal of Psychology, 91, 1-20.

Moghimi, D., Zacher, H., Scheibe, S., \& Van Yperen, N. W. (2017). The selection, optimization, and compensation model in the work context: A systematic review and meta-analysis of two decades of research. Journal of Organizational Behavior, 38(2), $247-275$.

Müller, A., Heiden, B., Herbig, B., Poppe, F., \& Angerer, P. (2016). Improving well-being at work: A randomized controlled intervention based on selection, optimization, and compensation. Journal of Occupational Health Psychology, 21(2), 169-181.

Müller, A., Weigl, M., Heiden, B., Glaser, J., \& Angerer, P. (2012). Promoting work ability and well-being in hospital nursing: the interplay of age, job control, and successful aging strategies. WORK: A Journal of Prevention, Assessment \& Rehabilitation, 41(1), $5137-5144$.

Muthén, L. K., \& Muthén, B. O. (1998-2011). Mplus User's Guide. Sixth Edition. Los Angeles, CA: Muthén \& Muthén. 
Ng, E. S. W., \& Law, A. (2014). Keeping up! Older workers' adaptation in the workplace after age 55. Canadian Journal on Aging, 33(1), 1-14

Ng, T. W. H., \& Feldman, D. C. (2008). The relationship of age to ten dimensions of job performance. Journal of Applied Psychology, 93(2), 392-423.

Ng, T. W. H., \& Feldman, D. C. (2010). Organizational tenure and job performance. Journal of Management, 36(5), 1220-1250.

Niessen, C., Sonnentag, S., \& Sach, F. (2012). Thriving at work - A diary study. Journal of Organizational Behavior, 33(4), 468-487.

O'Neil, D. A., \& Bilimoria, D. (2005). Women's career development phases: Idealism, endurance, and reinvention. Career Development International, 10(3), 168-189.

Paterson, T., Luthans, F., \& Jeung, W. (2014). Thriving at work: Impact of psychological capital and supervisor support. Journal of Organizational Behavior, 35(3), 434-446.

Porath, C., Spreitzer, G., Gibson, C., \& Garnett, F. G. (2012). Thriving at work: Toward its measurement, construct validation, and theoretical refinement. Journal of Organizational Behavior, 33(2), 250-275.

Preacher, K. J., \& Hayes, A. F. (2008). Asymptotic and resampling strategies for assessing and comparing indirect effects in multiple mediator models. Behavior Research Methods, 40, 879-891.

Roberts B. W., Walton K. E., \& Viechtbauer, W. (2006). Patterns of mean-level change in personality traits across the life course: A meta-analysis of longitudinal studies. Psychological Bulletin, 132(1), 1-25.

Rudolph, C. W. (2016). Lifespan developmental perspectives on working: a literature review of motivational theories. Work, Aging and Retirement, 2(2), 130-158.

Schwartz-Woelzl, M. T. \& Healey, M. (2007). Recruitment policies and practices in the context of demographic change: Critical issues in the ICT sector and 
recommendations. Retrieved from https://www.zsi.at/competence/20/attach/1_mature_final_report_2007.pdf.

Spreitzer, G. M., Porath, C. L., \& Gibson, C. B. (2012). Toward human sustainability: How to enable more thriving at work. Organizational Dynamics, 41(2), 155-162.

Spreitzer, G.M., Lam, C.F., \& Fritz, C. (2010). Engagement and human thriving: Complementary perspectives on energy and connections to work. In A.B. Bakker \& M.P. Leiter (Eds.), Work engagement: A handbook of essential theory and research (pp, 132-146). New York: Psychology Press.

Spreitzer, G. M., \& Sutcliffe, K. M. (2007). Thriving in organizations. In D. L. Nelson \& C. L. Cooper (Eds.), Positive Organizational Behavior. (pp. 74-85). London: Sage Publications Ltd.

Spreitzer, G. M., Sutcliffe, K. M., Dutton, J. Sonenshein, S., \& Grant, A. M. (2005). A socially embedded model of thriving at work. Organization Science, 16(5), 537-549.

Staufenbiel, T., \& König, C. J. (2010). A model for the effects of job insecurity on performance, turnover intention, and absenteeism. Journal of Occupational and Organizational Psychology, 83(1), 101-117.

Steiger, J. H. (1990). Structural model evaluation and modification: An interval estimation approach. Multivariate Behavioral Research, 25(2), 173-180.

Taneva, S. K., Arnold, J., \& Nicolson, R. (2016). The experience of being an older worker in an organization: a qualitative analysis. Work, Aging and Retirement, 2(4), 396-414.

Thrasher, G.R., Zabel, K., Wynne, K., \& Baltes, B. B. (2016). The importance of workplace motives in understanding work-family issues for older workers. Work, Aging and Retirement, 2(1), 1-11.

Tros, F. (2010). Flexibility and security for older workers: HRM arrangements in four European countries. In CEDEFOP: Working and ageing: emerging theories and 
empirical perspectives (pp. 132-166), Luxembourg: Publications Office of the European Union.

Truxillo, D. M., Cadiz, D. M., Rineer, J. R., Zaniboni, S., \& Fraccaroli, F. (2012). A lifespan perspective on job design: Fitting the job and the worker to promote job satisfaction, engagement, and performance. Organizational Psychology Review, 2(4), 340-360.

Veth, K. N., Emans, B. J. M., Van der Heijden, B. I. J. M., De Lange, A. H., \& Korzilius, H. P. L. M. (2011). Taking care of older workers: A multi-perspective case study on HR practices in health care organizations for older workers. https://www.academia.edu/2678702/Taking_care_of_older_worker

Viswesvaran, C., \& Ones, D. S. (2000). Perspectives on models of job performance. International Journal of Selection and Assessment, 8(4), 216-226.

Wang, M., Zhan, Y., Liu, S., \& Shultz, K. S. (2008). Antecedents of bridge employment: a longitudinal investigation. Journal of Applied Psychology, 93(4), 818-830.

Warr, P. (1993). In what circumstances does job performance vary with age? European Work and Organizational Psychologist, 3, 237-249.

Warr, P. (2001). Age and work behavior: Physical attributes, cognitive abilities, knowledge, personality traits and motives. In C. L. Cooper, \& I. T. Robertson (Eds.), International review of industrial and organizational psychology, 16 (pp, 1-36). New York: John Wiley \& Sons.

Whitley, R. (2016). Ethno-racial variation in recovery from severe mental illness: A qualitative comparison. The Canadian Journal of Psychiatry, 61(6), 340-347.

Weigl, M., Muller, A., Hornung, S., Zacher, H., \& Angerer, P. (2013). The moderating effects of job control and selection, optimization, and compensation strategies on the age-work ability relationship. Journal of Organizational Behavior, 34(5), 607-628. 
Williams, L. J., \& McGonagle, A. K. (2016). Four research designs and a comprehensive analysis strategy for investigating common method variance with self-report measures using latent variables. Journal of Business and Psychology, 31(3), 339-359.

Zacher, H. (2015a). Successful aging at work. Work, Aging and Retirement, 1(1), 4-25.

Zacher, H. (2015b). The importance of a precise definition, comprehensive model, and critical discussion of successful aging at work. Work, Aging and Retirement, 1(4), 320333.

Zacher, H., Chan, F., Bakker, A. B., \& Demerouti, E. (2015). Selection, optimization, and compensation strategies: Interactive effects on daily work engagement. Journal of Vocational Behavior, 87, 101-107.

Zacher, H., \& Frese, M. (2011). Maintaining a focus on opportunities at work: The interplay between age, job complexity, and the use of selection, optimization, and compensation strategies. Journal of Organizational Behavior, 32(2), 291-318. 
Table 1. Themes and Illustrative Quotes from Study 1

\begin{tabular}{|c|c|}
\hline $\begin{array}{c}\text { Theme identified from interview } \\
\text { transcripts (as per Armstrong- } \\
\text { Stassen, 2008a,b) }\end{array}$ & Illustrative interview quotes \\
\hline Training to learn new skills & $\begin{array}{l}\text { "I have always been really supported with learning. I have gone to the university to do my top-up } \\
\text { degree, then I went to a mentorship course, then to my assessor's course, and then I started this } \\
\text { master's module I am almost completing now...And all that... helped me particularly in that [new] } \\
\text { role." ( } 55+\text { worker, Health, UK). } \\
\text { "I found them [courses] interesting, but sometimes I think they are too generic and not really needed } \\
\text { for my job... So I stopped attending, because this also interferes with my work". (55+ worker, ICT, } \\
\text { UK). } \\
\text { "I've also been doing, additional to my role, more academic work. And this makes me proud of my } \\
\text { work....it's also about development." (55+ worker, Health, Bulgaria). }\end{array}$ \\
\hline Training to update current job skills & $\begin{array}{l}\text { "Yes, I think this [access to training and development opportunities] is necessary. In order to prevent } \\
\text { older workers from feeling isolated and unwanted after they reach formal retirement age, to give them } \\
\text { a chance to work and contribute even then." (55+ worker, Health, Bulgaria). (Also coded as } \\
\text { "opportunities to work past retirement"). } \\
\text { "We have had IT training.....how to switch on a computer. Which I had taken in 1998. So we had } \\
\text { basic training. The training now......you can ask the IT people about some work-related IT stuff." (55+ } \\
\text { worker, Health, UK). } \\
\text { "...perhaps make sure that people who retire and come back have access to training. They may think } \\
\text { they don't have to...I don't know. I suppose we could make sure that we promote more non- }\end{array}$ \\
\hline
\end{tabular}




\begin{tabular}{|c|c|}
\hline & $\begin{array}{l}\text { mandatory training and make sure that we promote it well." (HRM, Health, UK). (Also coded as } \\
\text { "opportunities to work past retirement"). }\end{array}$ \\
\hline $\begin{array}{l}\text { Challenging and meaningful tasks or } \\
\text { assignments }\end{array}$ & $\begin{array}{l}\text { "It depends on what the job role is......From the point of view of my own job role, I can say it could be } \\
\text { varied and as limited as you want it to be. So, if I just wanted to sit here and answer the phone, I } \\
\text { could." (55+ worker, ICT, UK). } \\
\text { "Yes, generally we are trying to engage our workforce around what they'd want to do, what career } \\
\text { path they would like to follow. They can have those conversations with their line managers, so that } \\
\text { they can do these jobs, smaller jobs, or different jobs." (HRM, ICT, UK). }\end{array}$ \\
\hline $\begin{array}{l}\text { Recognition of the significant role } \\
\text { mature employees can play }\end{array}$ & $\begin{array}{l}\text { Simply the fact that since I have been here for nine years, I am not just sitting in the same job I started } \\
\text { in. I think they recognize your expertise, experience, and knowledge, and if you want to move to a } \\
\text { different role and there's a vacancy, nothing will stop you doing it." (55+ worker, ICT, UK). } \\
\text { "...the suggestions which I make. My manager considers these suggestions and makes changes based } \\
\text { on them." ( } 55+\text { worker, Health, Bulgaria). } \\
\text { "... and we see older workers in our organization as having a lot of knowledge and being a great part } \\
\text { of our organization, so we want them to stay around to share their knowledge with maybe the younger } \\
\text { and less experienced workers." (HRM, ICT, UK). }\end{array}$ \\
\hline $\begin{array}{l}\text { Useful feedback from } \\
\text { supervisor/manager }\end{array}$ & $\begin{array}{l}\text { "The most useful feedback comes from our line manager. We do not have any detailed feedback from } \\
\text { the levels above." (55+ worker, ICT, Bulgaria). } \\
\text { "Appraisal is helpful, but I communicate with my boss and we say things openly to each other." ( } 55+ \\
\text { worker, ICT, UK). } \\
\text { "There's a mechanism for feedback and discussion. It's interesting. It's maybe more reluctant, } \\
\text { constrained from a younger manager to an older member of staff. I think it could be potentially }\end{array}$ \\
\hline
\end{tabular}




\begin{tabular}{|c|c|}
\hline & awkward at times, that sort of scenario...." (55+ worker, ICT, UK). \\
\hline $\begin{array}{l}\text { Financial incentives to remain in the } \\
\text { workforce instead of retiring }\end{array}$ & $\begin{array}{l}\text { "We have a good benefit, really (with our pension scheme). The most service you have got, the more } \\
\text { money you'll get at your retirement party - we do have that. We do gifts - the more years you have } \\
\text { got in the more money you get toward your gift when you leave." (HRM, Health, UK). } \\
\text { "[company name] offers as benefits the normal things really.... There's nothing specific for more } \\
\text { mature employees, but there are plenty of benefits within [company name] that are offered." (55+ } \\
\text { worker, ICT, UK). }\end{array}$ \\
\hline Unpaid additional leave & $\begin{array}{l}\text { "Nothing really, but we have additional annual leave. And this is for working extra hours." (55+ } \\
\text { worker, Health, Bulgaria). } \\
\text { "We do get additional annual leave that we can purchase, which I think is great." (55+ worker, ICT, } \\
\text { UK). } \\
\text { "Additional leave for some types of jobs." (HRM, Health, Bulgaria). }\end{array}$ \\
\hline $\begin{array}{l}\text { Opportunities to work past } \\
\text { retirement }\end{array}$ & $\begin{array}{l}\text { "We do like to retain skills in the business rather than lose them. We do sometimes bring people back } \\
\text { on a consultant basis... So, if someone retires and they want to come back on a contract basis." (HRM, } \\
\text { ICT, UK). } \\
\text { "There have been quite a few people who wanted to retire and before they retire, they would come and } \\
\text { ask if they could come back on a part-time plan or a number of hours that suits them." (HRM, Health, } \\
\text { UK). }\end{array}$ \\
\hline
\end{tabular}


Table 2: Means, Standard Deviations, Reliabilities, and Correlations of the Study Variables $(\mathrm{n}=853)$

\begin{tabular}{|c|c|c|c|c|c|c|c|c|c|c|c|c|c|c|}
\hline Variable & $\mathbf{M}$ & SD & $\alpha$ & OT & Sector & HR & ES & LBS & Opt & Comp & Thr & Surv & $\mathrm{TP}$ & IP \\
\hline $\begin{array}{l}\text { Organizational } \\
\text { Tenure (OT) }\end{array}$ & 4.51 & .02 & - & & & & & & & & & & & \\
\hline $\begin{array}{l}\text { Sector } \\
(1=\mathrm{HC} ; 2= \\
\text { ICT })\end{array}$ & 1.66 & .02 & - & $.270^{* *}$ & & & & & & & & & & \\
\hline $\begin{array}{l}\text { HR Practices } \\
(\mathrm{HR})\end{array}$ & 25.09 & .21 & .811 & -.066 & $-.115^{* *}$ & & & & & & & & & \\
\hline $\begin{array}{l}\text { Elective } \\
\text { Selection (ES) }\end{array}$ & 7.19 & .06 & .569 & .019 & .056 & .018 & & & & & & & & \\
\hline $\begin{array}{l}\text { Loss-based } \\
\text { Selection } \\
\text { (LBS) }\end{array}$ & 6.79 & .07 & .698 & -.010 & $-.084^{*}$ & $.109^{* *}$ & $.490^{* *}$ & & & & & & & \\
\hline $\begin{array}{l}\text { Optimization } \\
\text { (Opt) }\end{array}$ & 9.24 & .07 & .804 & -.015 & .009 & $.135^{* *}$ & $.330^{* *}$ & $.370^{* *}$ & & & & & & \\
\hline $\begin{array}{l}\text { Compensation } \\
\text { (Comp) }\end{array}$ & 7.97 & .07 & .722 & .004 & -.032 & $.098^{* *}$ & $.351^{* *}$ & $.481^{* *}$ & $.580^{* *}$ & & & & & \\
\hline $\begin{array}{l}\text { Thriving at } \\
\text { Work (Thr) }\end{array}$ & 29.41 & .25 & .878 & -.063 & $-.135^{* *}$ & $.457^{* *}$ & $.094^{* *}$ & $.177^{* *}$ & $.334^{* *}$ & $.261^{* *}$ & & & & \\
\hline
\end{tabular}




\begin{tabular}{|c|c|c|c|c|c|c|c|c|c|c|c|c|c|c|}
\hline $\begin{array}{l}\text { Surviving at } \\
\text { Work (Surv) }\end{array}$ & 9.92 & .08 & .699 & $.087^{*}$ & $.120^{* *}$ & $-.165^{* *}$ & $.097^{* *}$ & .041 & $-.105^{* *}$ & -.055 & $-.306^{* *}$ & & & \\
\hline $\begin{array}{l}\text { Task } \\
\text { Proactivity } \\
\text { (TP) }\end{array}$ & 10.75 & .08 & .907 & -.036 & -.045 & $.271^{* *}$ & .061 & $.168^{* *}$ & $.258^{* *}$ & $.226^{* *}$ & $.434^{* *}$ & $-.180^{* *}$ & & \\
\hline $\begin{array}{l}\text { In-role } \\
\text { Performance } \\
\text { (IP) }\end{array}$ & 17.11 & .08 & .802 & $-.139^{* *}$ & $-.180^{* *}$ & $.158^{* *}$ & $.076^{*}$ & $.143^{* *}$ & $.296^{* *}$ & $.247^{* *}$ & $.373^{* *}$ & $-.071^{*}$ & $.320^{* *}$ & \\
\hline $\begin{array}{l}\text { Extra-role } \\
\text { Performance } \\
(\mathrm{EP})\end{array}$ & 15.82 & .09 & .805 & -.011 & $-.085^{*}$ & $.275^{* *}$ & .067 & $.230 * *$ & $.322 * *$ & $.331 * *$ & $.430 * *$ & $-.220 * *$ & $.602 * *$ & $.433 * *$ \\
\hline
\end{tabular}

*. Correlation is significant at the 0.05 level (2-tailed).

**. Correlation is significant at the 0.01 level (2-tailed).

Note. Min and max possible scores: HR Practices 8, 40; Elective Selection 3, 12; Loss-based Selection 3, 12; Optimization 3, 12; Compensation 3, 12; Thriving at Work 6, 42; Surviving at Work 3, 15; Task Proactivity 3, 15; In-role Performance 4, 20; Extra-role Performance 4, 20. 
Running head: PATHWAYS TO SUCCESSFUL AGING AT WORK

Table 3: Confirmatory Factor Analysis (CFA) for Each Measure

\begin{tabular}{|c|c|c|c|c|c|c|}
\hline Model & $\begin{array}{c}\chi^{2} \\
\text { (d.f.) }\end{array}$ & Sig. & CFI & TLI & RMSEA, CI & SRMR \\
\hline 1-Factor Overall job performance & $1453.376(35)$ & $\mathrm{p}<.001$ & .686 & .596 & $.218,90 \%$ CI $[.208, .228]$ & .136 \\
\hline $\begin{array}{l}\text { 3-Factor Job Performance: Task } \\
\text { Proactivity, In-role Performance, and } \\
\text { Extra-role Performance }\end{array}$ & $302.560(41)$ & $\mathrm{p}<.001$ & .945 & .927 & $.086,90 \%$ CI $[.077, .096]$ & .055 \\
\hline $\begin{array}{l}\text { 4-Factor Use of SOC strategies: Elective } \\
\text { Selection, Loss-based Selection, } \\
\text { Compensation, and Optimization }\end{array}$ & $261.170(48)$ & $\mathrm{p}<.001$ & .935 & .911 & $.072,90 \%$ CI $[.064, .081]$ & .045 \\
\hline 1-Factor Thriving at Work (with all 10 items) & $1133.866(33)$ & $\mathrm{p}<.001$ & .820 & .754 & $.198,90 \%$ CI $[.188, .208]$ & .129 \\
\hline 1-Factor Thriving at Work (with 6 items) & $21.648(6)$ & $\mathrm{p}<.001$ & .996 & .990 & $.055,90 \%$ CI $[.031, .081]$ & .017 \\
\hline $\begin{array}{l}\text { 2-Factor Thriving at Work: Vitality \& } \\
\text { Learning (with } 6 \text { items) }\end{array}$ & $20.088(5)$ & $\mathrm{p}<.001$ & .996 & .988 & $.059,90 \%$ CI $[.034, .088]$ & .014 \\
\hline 1-Factor Surviving at Work & $16.343(2)$ & $\mathrm{p}<.001$ & .968 & .953 & $.092,90 \%$ CI $[.054, .135]$ & .066 \\
\hline
\end{tabular}


Running head: PATHWAYS TO SUCCESSFUL AGING AT WORK

\begin{tabular}{|l|c|l|l|l|l|l|}
\hline & & & & & & \\
\hline 1-Factor HR (pre-modification) & $472.124(20)$ & $\mathrm{p}<.001$ & .817 & .743 & $.163,90 \% \mathrm{CI}[.150, .176]$ & .09 \\
\hline 1-Factor HR (post- modification) & $\mathbf{7 5 . 2 5 1}(\mathbf{1 7})$ & $\mathbf{p}<.001$ & $\mathbf{. 9 7 6}$ & $\mathbf{. 9 6 1}$ & $\mathbf{. 0 6 3 , 9 0 \%} \mathbf{C I}[\mathbf{. 0 4 9 , . 0 7 8}]$ & $\mathbf{. 0 3 4}$ \\
\hline
\end{tabular}

Note. The models selected for subsequent analyses are highlighted in bold.

65

5

7

8 
Table 4: Confirmatory Factor Analysis for the Alternative Measurement Models

\begin{tabular}{|c|c|c|c|c|c|c|}
\hline Model & $\begin{array}{c}\chi^{2} \\
\text { (d.f.) }\end{array}$ & Sig. & CFI & TLI & RMSEA, CI & SRMR \\
\hline Model 1: One common factor & $8361.636(696)$ & $\mathrm{p}<.001$ & .515 & .484 & $.114,90 \%$ CI $[.111, .116]$ & .109 \\
\hline $\begin{array}{l}\text { Model 2: Five factors (HR Practices, } \\
\text { Thriving at Work, Surviving at Work, } \\
\text { Overall Use of SOC strategies, and } \\
\text { Overall Job Performance) }\end{array}$ & $3786.800(686)$ & $\mathrm{p}<.001$ & .804 & .788 & $.073,90 \%$ CI $[.071, .075]$ & .078 \\
\hline $\begin{array}{l}\text { Model } 3 \text { (hypothesized): } \\
\text { Ten factors (HR Practices, Thriving a } \\
\text { Work, Surviving at Work, Elective } \\
\text { Selection, Loss-based Selection, } \\
\text { Compensation, Optimization, Task } \\
\text { Proactivity, In-role Performance, and } \\
\text { Extra-role Performance) }\end{array}$ & $1800.881(651)$ & $\mathrm{p}<.001$ & .927 & .917 & $.046,90 \%$ CI $[.043, .048]$ & .059 \\
\hline
\end{tabular}


Running head: PATHWAYS TO SUCCESSFUL AGING AT WORK

Figure 1: Conceptual Model

H6

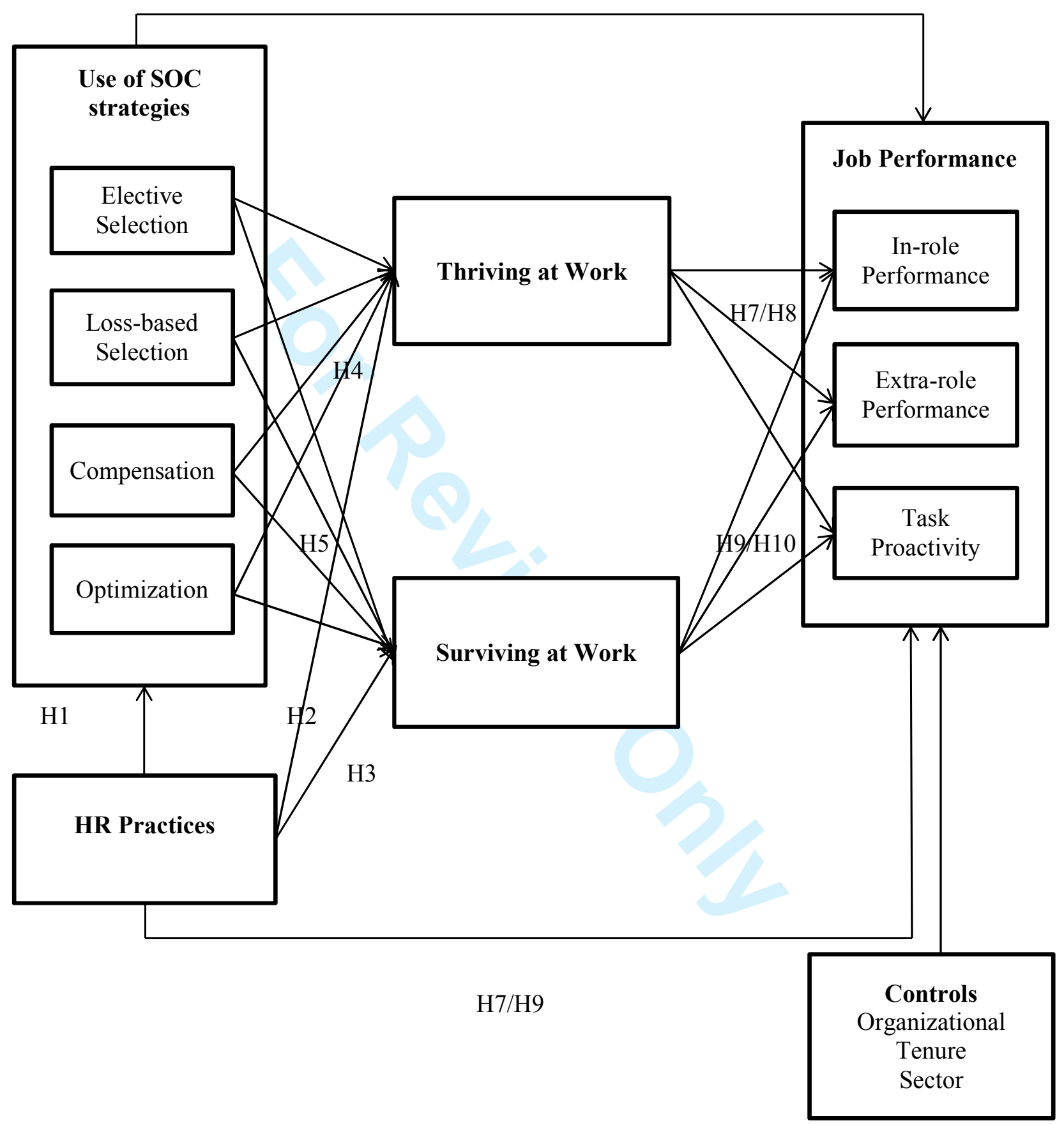


Figure 2. Results from Testing Research Hypotheses (Significant Relationships Only)

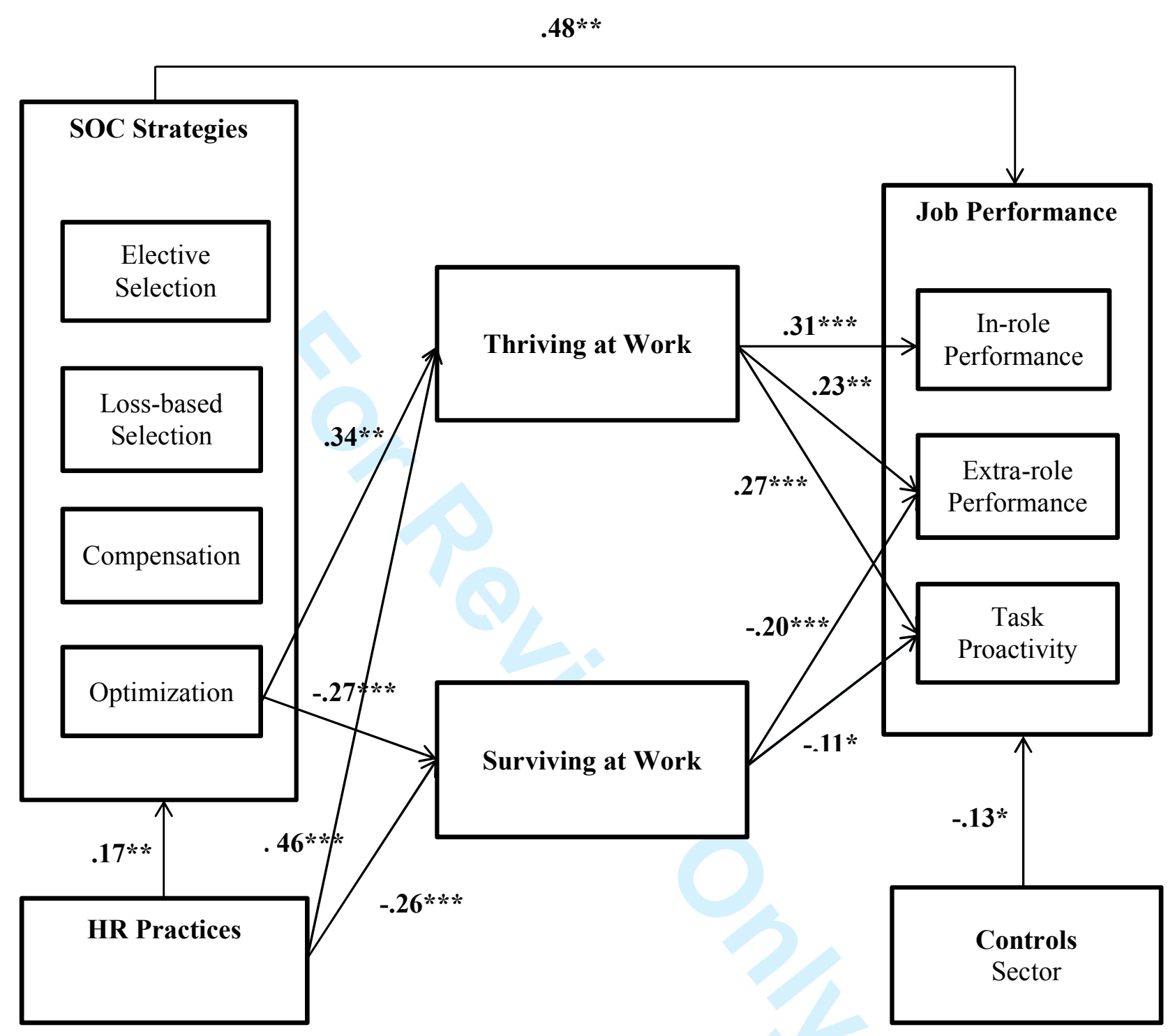


Appendix 1: Confirmatory Factor Analysis of the 10-Factor Model: Standardized Factor Loadings and R-Square (in Parenthesis)

\begin{tabular}{|c|c|c|c|c|c|c|c|c|c|c|}
\hline & \multicolumn{10}{|c|}{ Factor } \\
\hline & 1 & 2 & 3 & 4 & 5 & 6 & 7 & 8 & 9 & 10 \\
\hline \multicolumn{11}{|l|}{ Available HR Practices } \\
\hline Unpaid (additional) leave. & $\begin{array}{c}.37 \\
(0.13)\end{array}$ & & & & & & & & & \\
\hline Training to update current job skills. & $\begin{array}{c}.66 \\
(0.43)\end{array}$ & & & & & & & & & \\
\hline Training to learn new skills. & $\begin{array}{l}\mathbf{0 . 6 7} \\
(0.45)\end{array}$ & & & & & & & & & \\
\hline $\begin{array}{l}\text { Challenging and meaningful tasks or } \\
\text { assignments. }\end{array}$ & $\begin{array}{l}\mathbf{0 . 6 9} \\
(0.47)\end{array}$ & & & & & & & & & \\
\hline Useful feedback from supervisor/manager. & $\begin{array}{c}\mathbf{0 . 7 1} \\
(0.51)\end{array}$ & & & & & & & & & \\
\hline $\begin{array}{l}\text { Financial incentives to remain in the workforce } \\
\text { instead of retiring. }\end{array}$ & $\begin{array}{c}\mathbf{0 . 5 1} \\
(0.26)\end{array}$ & & & & & & & & & \\
\hline $\begin{array}{l}\text { Recognition of the significant role mature } \\
\text { employees can play. }\end{array}$ & $\begin{array}{c}\mathbf{0 . 6 1} \\
(0.38)\end{array}$ & & & & & & & & & \\
\hline Opportunities to work past retirement. & $\begin{array}{c}\mathbf{0 . 4} \\
(0.16)\end{array}$ & & & & & & & & & \\
\hline \multicolumn{11}{|l|}{ Thriving at Work } \\
\hline I find myself learning often. & & $\begin{array}{c}\mathbf{0 . 4} \\
(.16)\end{array}$ & & & & & & & & \\
\hline I continue to learn more as time goes by. & & 0.45 & & & & & & & & \\
\hline
\end{tabular}


I see myself continually improving.

I am not learning $(R)$.

I am not learning (R)

I am developing a lot as a person.

I feel alive and vital.

0.95

I have energy and spirit.

(0.9)

$\mathbf{0 . 9 1}$

I am looking forward to each new day.

0.81

I do not feel very energetic (R).

Ifeel alert and awake.

\section{Surviving at Work (Protecting the Status} Quo)

My purpose now is to maintain the status quo at work.

I am mostly interested to learn only the things

My goal now is to keep interested in my work without going to the next level of stress.

0.58

$(0.33)$ 


\section{Elective Selection}

I concentrate all my energy on few things. $\quad \mathbf{0 . 3 1}$

I always focus on the one most important goal at

a given time. $\quad(0.28)$

When I think about what I want in life, I commit $\quad \mathbf{0 . 7 6}$

myself to one or two important goals.

\section{Loss-based Selection}

When things don't go as well as they have in the past, I choose one or two important goals.

When I can't do something important the way I

did before, I look for a new goal.

When I can't do something as well as I used to, I think about my priorities and what exactly is important to me.

\section{Compensation}

I keep working on what I have planned until I succeed.

I make every effort to achieve a given goal.

If something matters to me, I devote myself 


\section{Optimization}

When things don't go as well as they used to, I keep trying other ways until I can achieve the same result I used to.

0.8

$(0.64)$

$\mathbf{0 . 8 2}$

(0.67)

0.67

$(0.45)$

When it becomes harder for me to get the same results, I keep trying harder until I can do it as well as before.

\section{Task Proactivity}

I initiate better ways of doing my core tasks.

I come up with ideas to improve the way in which my core tasks are done.

I make changes to the way my core tasks are done.

\section{In-role Performance}

I adequately complete assigned duties.

0.72

$(0.52)$

I fulfil the responsibilities specified in my job description.

I work cooperatively with my supervisor. 
I meet formal performance requirements of the job.

\section{Extra-role Performance}

I make constructive suggestions to improve the

overall functioning of my work group.

I encourage others to try new and more effective

ways of doing their job.

I continue to look for new ways to improve the

I go out my way to help new employees.

Note. All factors load at $\mathrm{p}<.001$; Items in italic were not included in further analyses 
Running head: PATHWAYS TO SUCCESSFUL AGING AT WORK

Appendix 2: Standardized Path Estimates for the Structural Model

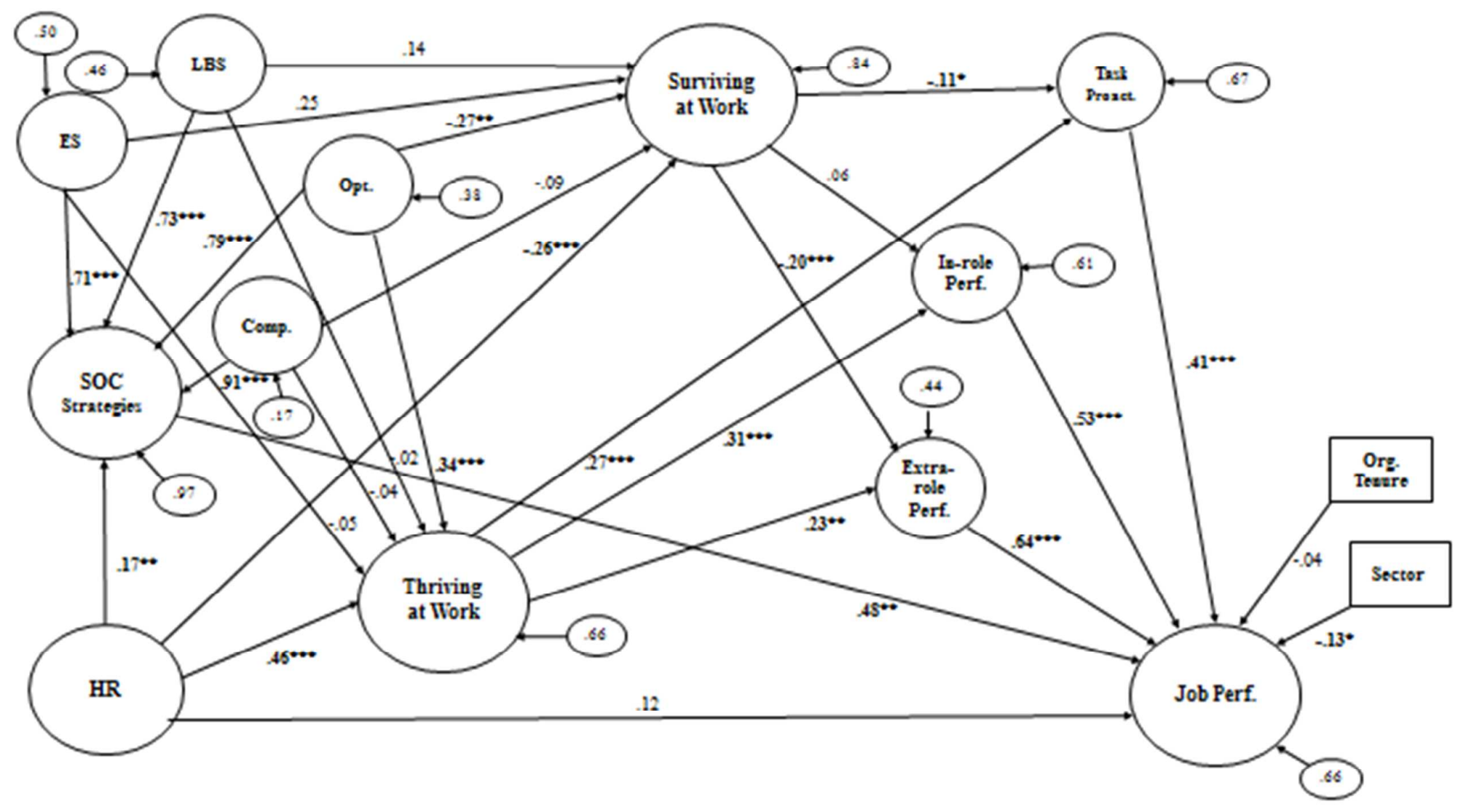

